\title{
Enabling highly efficient and broadband electromagnetic wave absorption by tuning impedance match in high-entropy transition metal diborides $\left(\mathrm{HE} \mathrm{TMB}_{2}\right)$
}

\author{
Weiming ZHANG ${ }^{a}$, Fu-Zhi DAI ${ }^{a}$, Huimin $\mathrm{XIANG}^{a}$, Biao ZHAO ${ }^{b}$, \\ Xiaohui $\mathrm{WANG}^{c}, \mathrm{Na} \mathrm{NI}^{d}$, Rajamallu $\mathrm{KARRE}^{d}$, \\ Shijiang $\mathrm{WU}^{e}$, Yanchun $\mathrm{ZHOU}^{a, *}$ \\ ${ }^{a}$ Science and Technology on Advanced Functional Composite Laboratory, Aerospace Research Institute of \\ Materials \& Processing Technology, Beijing 100076, China \\ ${ }^{b}$ Henan Key Laboratory of Aeronautical Materials and Application Technology, School of Material Science and \\ Engineering, Zhengzhou University of Aeronautics, Zhengzhou 450046, China \\ 'Shenyang National Laboratory for Materials Science, Institute of Metal Research, \\ Chinese Academy of Sciences, Shenyang 110016, China \\ ${ }^{d}$ Key Lab of Education Ministry for Power Machinery and Engineering, School of Mechanical Engineering, \\ Shanghai Jiao Tong University, Shanghai 200240, China \\ ${ }^{e}$ Zibo Firststar New Material Incorporated Co., Ltd., Zibo 255000, China
}

Received: March 21, 2021; Revised: May 11, 2021; Accepted: June 3, 2021

(C) The Author(s) 2021.

\begin{abstract}
The advance in communication technology has triggered worldwide concern on electromagnetic wave pollution. To cope with this challenge, exploring high-performance electromagnetic (EM) wave absorbing materials with dielectric and magnetic losses coupling is urgently required. Of the EM wave absorbers, transition metal diborides $\left(\mathrm{TMB}_{2}\right)$ possess excellent dielectric loss capability. However, akin to other single dielectric materials, poor impedance match leads to inferior performance. High-entropy engineering is expected to be effective in tailoring the balance between dielectric and magnetic losses through compositional design. Herein, three $\mathrm{HE} \mathrm{TMB}_{2}$ powders with nominal equimolar $\mathrm{TM}$ including $\mathrm{HE} \mathrm{TMB}_{2}-1(\mathrm{TM}=\mathrm{Zr}, \mathrm{Hf}, \mathrm{Nb}, \mathrm{Ta}), \mathrm{HE} \mathrm{TMB}_{2}-2$ $(\mathrm{TM}=\mathrm{Ti}, \mathrm{Zr}, \mathrm{Hf}, \mathrm{Nb}, \mathrm{Ta})$, and $\mathrm{HE}_{\mathrm{TMB}}-3(\mathrm{TM}=\mathrm{Cr}, \mathrm{Zr}, \mathrm{Hf}, \mathrm{Nb}, \mathrm{Ta})$ have been designed and prepared by one-step boro/carbothermal reduction. As a result of synergistic effects of strong attenuation capability and impedance match, $\mathrm{HE} \mathrm{TMB}_{2}-1$ shows much improved performance with the optimal minimum reflection loss $\left(\mathrm{RL}_{\min }\right)$ of $-59.6 \mathrm{~dB}(8.48 \mathrm{GHz}, 2.68 \mathrm{~mm})$ and effective absorption bandwidth (EAB) of $7.6 \mathrm{GHz}(2.3 \mathrm{~mm})$. Most impressively, incorporating $\mathrm{Cr}$ in $\mathrm{HE}$ $\mathrm{TMB}_{2}-3$ greatly improves the impedance match over $1-18 \mathrm{GHz}$, thus achieving the $\mathrm{RL}_{\text {min }}$ of $-56.2 \mathrm{~dB}$ $(8.48 \mathrm{GHz}, 2.63 \mathrm{~mm})$ and the EAB of $11.0 \mathrm{GHz}(2.2 \mathrm{~mm})$, which is superior to most other EM wave absorbing materials. This work reveals that constructing high-entropy compounds, especially by incorporating magnetic elements, is effectual in tailoring the impedance match for highly conductive compounds, i.e., tuning electrical conductivity and boosting magnetic loss to realize highly efficient and broadband EM wave absorption with dielectric and magnetic coupling in
\end{abstract}

\footnotetext{
* Corresponding author.

E-mail: yczhou@alum.imr.ac.cn
} 
single-phase materials.

Keywords: transition metal diboride $\left(\mathrm{TMB}_{2}\right)$; high-entropy (HE) ceramics; electronic structure; microwave absorption; dielectric and magnetic losses coupling

\section{Introduction}

The ubiquitous electromagnetic (EM) wave pollutions accompanying the massive usage of wireless communication technologies have evolved into worldwide threats, which have harmful impacts on not only biological health but also normal operation of electronic devices [1-3]. To tackle this hazard, EM wave absorbing materials that are capable of converting EM energy into thermal energy or other forms of energy have drawn considerable attentions $[4,5]$. Thus, significant efforts have been made on exploring EM wave absorbing materials with thin thickness, light weight, high efficiency, and broadband absorption over decades.

In essence, the absorption of EM energy is implemented by the interactions between electric and/or magnetic dipoles of materials and EM waves. Since EM waves are made up of oscillating electric and magnetic fields, the attenuation of one of them will lead to a corresponding change of the other, which in turn results in the dissipations of the entire EM waves [4]. To date, a bunch of EM wave absorbing materials based on dielectric loss or magnetic loss mechanism have been developed. For instance, dielectric loss-type absorbers include carbon fiber (CF) [6], carbon nanotube (CNT) [7], reduced graphene oxide ( $\mathrm{rGO}$ ) [8], conductive polymer [9], oxides (silicon oxide [10], zinc oxide [11], etc.), transition metal sulfides [12], silicon carbide [13], and 2D transition metal carbides/ nitrides/carbonitrides (MXenes) [14], and magnetic loss-type absorbers consist of ferrites [15-17] and magnetic metals [18-20]. Although dielectric loss-type EM absorbing materials exhibit high attenuation constant $(\alpha)$ mainly derived from dielectric loss, they are still hindered by limited absorption capacity and narrow effective absorption bandwidth (EAB) due to the mismatch between the complex permittivity and the complex permeability. In specific, highly conductive materials tend to form conductive framework at the surface and result in skin effects, which prevent the EM waves from penetrating into materials and reduce the occurrence of multi-attenuations [6,7]. As for magnetic loss-type absorbers, they take advantages of a proper magnetization value and a relatively high Curie temperature but also suffer from a sudden decrease of permeability in high frequency due to the Snoek's limit $[16,21,22]$. Hence, various efforts have been carried out to realize dielectric and magnetic losses coupling and impedance matching, which can be achieved through composite construction [6,16,23-25], elemental doping [10], and structural design [26,27]. Although impedance match can be effectively achieved by the foregoing methods, complex experimental procedures and difficulties in accurately controlling nanostructures and interfaces are still unignorable issues. In addition, for applications in high-temperature environments, problems including poor thermal stability, oxidation susceptibility, and inferior corrosion resistance also need to be solved. It is thus significant to realize dielectric and magnetic losses coupling in single-phase materials that possess highly efficient EM wave absorption performance, easy processability, good thermal stability, and good resistance to oxidation and corrosion.

As the main member of the ultrahigh temperature ceramic (UHTC) family, transition metal diborides $\left(\mathrm{TMB}_{2}\right)$ crystallize in a $\mathrm{AlB}_{2}$-type hexagonal structure with metallic bonding between $\mathrm{TM}$ atoms, ioniccovalent bonding between $\mathrm{TM}$ and $\mathrm{B}$ atoms, and covalent bonding between $\mathrm{B}$ atoms, which endow them high melting temperature, good thermal and chemical stabilities, good oxidation and corrosion resistance, as well as high electrical and thermal conductivities [28-31]. Intriguingly, in the crystal structure of $\mathrm{TMB}_{2}$, there exhibit alternatingly graphite-like boron layers and transition metal layers, whose metallic features derived mainly from TM $d$ states and partly from B $2 p_{\mathrm{z}}$ states [30-32]. Generally, the interaction between the incident electric field and electric dipoles leading to the dissipation of electromagnetic energy is referred as the dielectric loss ability, which counts on conductivity loss and relaxation polarizations in $\mathrm{GHz}$ range [33]. The electron migration due to the natural electrical conductivity of $\mathrm{TMB}_{2}$ will lead to the reduction of electromagnetic energy in the form of conduction loss. 
In this light, $\mathrm{TMB}_{2}$ with good thermal stability, oxidation and corrosion resistance, and good dielectric loss capability are promising as EM wave absorbing materials. However, akin to the foregoing dielectric loss-type absorbers, the conductivity of $\mathrm{TMB}_{2}$ is too high that a continuous conduction current is formed at the surface, which leads to poor impedance match and inferior EM wave absorption performance [6,7]. As demonstrated by Jian et al. [34], the reflection loss (RL) values of pure $\mathrm{ZrB}_{2}$ are larger than $-5 \mathrm{~dB}$ within the thickness of $1-5 \mathrm{~mm}$ in the frequency range of $2-18$ GHz. Therefore, it is necessary to tailor the balance between dielectric loss and magnetic loss in $\mathrm{TMB}_{2}$ for achieving efficient and broadband EM wave absorption capability.

In the light of localized states of TM $d$ and $\mathrm{B} p$ electrons in $\mathrm{TMB}_{2}$, the electrical conductivity can be tuned by controlling the disorder in a fixed system size, i.e., with the same carrier density, the increasing of the degree of randomness in a fixed lattice can lead to the reduction of conductivity due to enhanced electron and phonon scattering [30,31,35-37]. Inspiringly, incorporating multiple principle elemental species into a single lattice with random occupancy is an effective way to increase the entropy and swell the randomness in the lattice [38-40]. In specific, according to Boltzmann's equation about the relationship of the configurational entropy per mole $\left(\Delta S_{\text {conf }}\right)$ and the complexion of a system $\left(\Delta S_{\text {conf }}=R \ln n\right)$, the entropy increases with the number of elements $(n)$ and reaches its maximum when all the species possess the same fraction $[38,39]$. Thus, it is an effective and efficient way to tune the electrical conductivity by developing high-entropy transition metal diboride $\left(\mathrm{HE} \mathrm{TMB}_{2}\right)$.

In addition to tuning the electrical conductivity, enhancing magnetic loss ability through compositional design is also a key approach to realize impedance matching. Due to the paramagnetic features of $\mathrm{TMB}_{2}$ ( $\mathrm{TM}=\mathrm{Ti}, \mathrm{Zr}, \mathrm{Hf}, \mathrm{Nb}, \mathrm{Ta}$, etc.), their magnetic loss capabilities are often overlooked [34,41,42]. However, the magnetic loss capabilities of $\mathrm{TMB}_{2}$ at $\mathrm{GHz}$ range are worthy of noting based on the following reasons. Firstly, due to the absence of unpaired electrons, most $\mathrm{TMB}_{2}(\mathrm{TM}=\mathrm{Ti}, \mathrm{Zr}, \mathrm{Hf}, \mathrm{Nb}, \mathrm{Ta}$, etc.) exhibit no magnetic ordering without external magnetic field but show anisotropy of magnetic susceptibility along and perpendicular to the six-fold $c$-axis of the hexagonal structure encountering alternating EM wave magnetic field, which might lead to resonance loss correlating to the anisotropy field [27]. Secondly, experimental works have found that $\mathrm{CrB}_{2}$ exhibits chromium-like antiferromagnetic helical magnetic structure [43,44], which is expected to possess high permeability. Especially when $\mathrm{HE} \mathrm{TMB}$ is formed with severe lattice distortion, an extra energy consumption is expected for the realignment of antiparallel spin moments. Therefore, incorporating $\mathrm{CrB}_{2}$ into $\mathrm{HE} \mathrm{TMB}_{2}$ contributes to the decreased permittivity but increased permeability, which will further result in the improved impedance match as well as strong and broadband absorption performance. Thirdly, a host of defects are introduced by high configurational entropy construction in $\mathrm{HE}$ $\mathrm{TMB}_{2}$, which exhibit spin paramagnetism to some extent due to the presence of unpaired electron. Under alternating magnetic field at $\mathrm{GHz}$, the electronic transition from the lower energy state to the higher one is expected to attenuate microwave energy intensely, which is known as electron paramagnetic resonance (EPR) $[45,46]$. Besides, the five $d$-orbitals of transition metals in $\mathrm{HE} \mathrm{TMB}_{2}$ under a combination of coulombic attraction and bonding interactions are expected to go through energy-level splitting. The crystal fieldsplitting energy is tunable by adjusting the metal ion, and the interconversion between different energy levels responding to electromagnetic field or heat will also lead to considerable permeability [47]. Last but not least, in addition to tunable EM parameters [47-50], the construction of $\mathrm{HE} \mathrm{TMB}_{2}$ will also display a host of unexpected properties including better hightemperature stability [51-53], better oxidation resistance [54], and improved resistance to corrosion and environmental attack [55]. Therefore, it is promising to realize highly efficient and broadband EM wave absorption in $\mathrm{HE} \mathrm{TMB}_{2}$ with good thermal stability, good oxidation, and corrosion resistance.

Aiming at realizing dielectric and magnetic losses coupling and tuning the impedance match through forming high-entropy ceramics, three $\mathrm{HE} \mathrm{TMB}_{2}$ including $\left(\mathrm{Zr}_{0.25} \mathrm{Hf}_{0.25} \mathrm{Nb}_{0.25} \mathrm{Ta}_{0.25}\right) \mathrm{B}_{2},\left(\mathrm{Ti}_{0.2} \mathrm{Zr}_{0.2} \mathrm{Hf}_{0.2} \mathrm{Nb}_{0.2} \mathrm{Ta}_{0.2}\right) \mathrm{B}_{2}$, and $\left(\mathrm{Cr}_{0.2} \mathrm{Zr}_{0.2} \mathrm{Hf}_{0.2} \mathrm{Nb}_{0.2} \mathrm{Ta}_{0.2}\right) \mathrm{B}_{2}$ are designed as new EM wave absorbing materials, which henceforward are referred to $\mathrm{HE} \mathrm{TMB}_{2}-1, \mathrm{HE} \mathrm{TMB}_{2}-2$, and $\mathrm{HE} \mathrm{TMB}_{2}-3$, respectively. The selection of transition metal elements in $\mathrm{HE} \mathrm{TMB}_{2} \mathrm{~S}$ is due to the following considerations. Firstly, $\mathrm{TMB}_{2} \mathrm{~s}(\mathrm{TM}=\mathrm{Ti}, \mathrm{Zr}, \mathrm{Hf}, \mathrm{Nb}, \mathrm{Ta}, \mathrm{Cr})$ exhibit the same hexagonal crystal structure. Secondly, the 
utilizations of magnetic anisotropy, defect electron spin resonance, and $d$-orbitals splitting features in $\mathrm{TMB}_{2} \mathrm{~S}$ $(\mathrm{TM}=\mathrm{Ti}, \mathrm{Zr}, \mathrm{Hf})$ contribute to the magnetic loss. Thirdly, the effects of incorporating nonmagnetic $\mathrm{TiB}_{2}$ and antiferromagnetic $\mathrm{CrB}_{2}$ on EM wave absorption performance are investigated. Fourthly, the coupling effects of dielectric and magnetic losses are expected considering dual electromagnetic properties, i.e., tailored balance between permittivity and permeability. Fifthly, except for $\mathrm{CrB}_{2}, \mathrm{TMB}_{2} \mathrm{~S}(\mathrm{TM}=\mathrm{Ti}, \mathrm{Zr}, \mathrm{Hf}, \mathrm{Nb}$, Ta) possess high melting point around $3000{ }^{\circ} \mathrm{C}$, while the existence of $\mathrm{Cr}$ element is beneficial to form a protective $\mathrm{Cr}_{2} \mathrm{O}_{3}$ layer and improve oxidation resistance. Therefore, the formation of $\mathrm{HE}^{\mathrm{TMB}} \mathrm{TM}_{2}$ could lead to further improvement of overall properties including thermal stability, oxidation and corrosion resistance, and EM wave absorption performance.

\section{Materials and method}

\section{1 Theoretical investigation on electronic structure and magnetic properties of $\mathrm{TMB}_{2}$}

To elucidate the electronic structure and magnetic properties of $\mathrm{TMB}_{2}$, first-principles calculations were carried out using density functional theory (DFT) implemented in the Cambridge Serial Total Energy Package (CASTEP) code [56]. In this work, the Vanderbilt-type ultra-soft pseudopotential [57] and generalized gradient approximation (GGA) based on the Perdew-Burke-Ernerhof (PBE) scheme were employed [58]. For all calculations, the plane-wave basis set cutoff energy was $450 \mathrm{eV}$, and a $10 \times 10 \times 8$ special k-point mesh according to Monkhorst-Pack method [59] was adopted over the Brillouin zone. Geometry optimization was performed using the Broyden-Fletcher-Goldfarb-Shanno (BFGS) minimization scheme [60]. The convergence thresholds for cell optimization are difference on total energy within $5 \times$ $10^{-6} \mathrm{eV} /$ atom, maximum ionic Hellmann-Feynman force within $0.01 \mathrm{eV} / \AA$, maximum stress within 0.02 $\mathrm{GPa}$, and maximum ionic displacement within $5 \times 10^{-4}$ $\AA$. To evaluate the bonding nature of $\mathrm{TMB}_{2}$, Mulliken population analysis [61,62] was carried out with a constant basis set. To investigate the magnetic properties of $\mathrm{CrB}_{2}$, spin-polarized calculations were performed on $\mathrm{CrB}_{2}$ [63]. Besides, the calculations of projected density of states were performed using a projection of the plane-wave electronic states onto a localized linear combination of atomic orbitals (LCAO) basis set. To study the effects of incorporating $\mathrm{CrB}_{2}$ into $\mathrm{TiB}_{2}$ without non-full $d$ subshell, spin-polarized calculations were performed on $\left(\mathrm{Ti}_{1-x} \mathrm{Cr}_{x}\right) \mathrm{B}_{2}(x=0,0.25,0.5,0.75)$ solid solutions, where $2 \times 2 \times 1$ supercells were used.

\section{2 Synthesis of $\mathrm{HE} \mathrm{TMB}_{2}$ powders}

To investigate the EM wave absorption performance of $\mathrm{HE} \mathrm{TMB}_{2}$, three HE $\mathrm{TMB}_{2} \mathrm{~S}$ were designed and then synthesized by boro/carbothermal reduction (BCTR) approach according to Reactions (1)-(3):

$$
\begin{aligned}
2 \mathrm{TMO}_{2}+\frac{10}{7} \mathrm{~B}_{4} \mathrm{C} & =2 \mathrm{TMB}_{2}+\frac{6}{7} \mathrm{~B}_{2} \mathrm{O}_{3}+\frac{10}{7} \mathrm{CO} \\
(\mathrm{TM} & =\mathrm{Ti}, \mathrm{Zr}, \mathrm{Hf}) \\
\mathrm{TM}_{2} \mathrm{O}_{5}+\frac{11}{7} \mathrm{~B}_{4} \mathrm{C} & =2 \mathrm{TMB}_{2}+\frac{8}{7} \mathrm{~B}_{2} \mathrm{O}_{3}+\frac{11}{7} \mathrm{CO} \\
(\mathrm{TM} & =\mathrm{Nb}, \mathrm{Ta}) \\
\mathrm{Cr}_{2} \mathrm{O}_{3}+\frac{9}{7} \mathrm{~B}_{4} \mathrm{C} & =2 \mathrm{TMB}_{2}+\frac{4}{7} \mathrm{~B}_{2} \mathrm{O}_{3}+\frac{8}{7} \mathrm{CO}
\end{aligned}
$$

Transition metal oxides $\left(\mathrm{TiO}_{2}, \mathrm{Cr}_{2} \mathrm{O}_{3}, \mathrm{ZrO}_{2}, \mathrm{HfO}_{2}\right.$, $\mathrm{Nb}_{2} \mathrm{O}_{5}, \mathrm{Ta}_{2} \mathrm{O}_{5}, 99.9 \%$ purity, $1 \mu \mathrm{m}$; China New Materials Technology Co., Ltd., Beijing, China) and $\mathrm{B}_{4} \mathrm{C}$ powders (98\% purity, -200 mesh; Mudanjiang Qianjin Reagent Co., Ltd., Heilongjiang, China) were used as the starting reactants. Considering the evaporation of boron oxides (i.e., $\mathrm{B}_{2} \mathrm{O}_{3}$ and $\mathrm{BO}$ ) at high temperature in vacuum, $10 \mathrm{wt} \%$ excess $\mathrm{B}_{4} \mathrm{C}$ was added to compensate for the loss of boron source [64].

For the synthesis of $\mathrm{HE} \mathrm{TMB}_{2}$ powders, the starting reactants with the molar ratio of transition metal oxides and boron-carbide powders listed in Table 1 were weighted and thoroughly mixed in an agate mortar. The mixed powders were uniaxially pelletized in a stainless-steel die to obtain cylindrical pellets of $12 \mathrm{~mm}$ in diameter. The pellets were then calcined at $1950{ }^{\circ} \mathrm{C}$ for $1 \mathrm{~h}$ in vacuum. Finally, the as-prepared pellets were crushed, grounded in an agate mortar, and then sieved through a 120 -mesh screen for subsequent characterizations.

Table 1 Constituent of raw materials used for synthesizing $\mathrm{HE}$ TMB 2 powders

\begin{tabular}{cc}
\hline $\mathrm{HE} \mathrm{TMB}_{2}$ & \multicolumn{1}{c}{ Molar ratio of the raw reactant } \\
\hline $\mathrm{HE} \mathrm{TMB}_{2}-1$ & $\mathrm{ZrO}_{2}: \mathrm{HfO}_{2}: \mathrm{Nb}_{2} \mathrm{O}_{5}: \mathrm{Ta}_{2} \mathrm{O}_{5}: \mathrm{B}_{4} \mathrm{C}=2: 2: 1: 1: 6.6$ \\
& $\mathrm{TiO}_{2}: \mathrm{ZrO}_{2}: \mathrm{HfO}_{2}: \mathrm{Nb}_{2} \mathrm{O}_{5}: \mathrm{Ta}_{2} \mathrm{O}_{5}: \mathrm{B}_{4} \mathrm{C}$ \\
& $=2: 2: 2: 1: 1: 8.17$ \\
$\mathrm{HE} \mathrm{TMB}_{2}-2$ & $\mathrm{Cr}_{2} \mathrm{O}_{3}: \mathrm{ZrO}_{2}: \mathrm{HfO}_{2}: \mathrm{Nb}_{2} \mathrm{O}_{5}: \mathrm{Ta}_{2} \mathrm{O}_{5}: \mathrm{B}_{4} \mathrm{C}$ \\
& $=2: 2: 2: 1: 1: 8.01$ \\
$\mathrm{HE} \mathrm{TMB}$ & \\
&
\end{tabular}




\section{3 Characterization}

Phase composition was analyzed by an X-ray diffractometer (XRD; D8 Advanced, Bruker, Germany) utilizing $\mathrm{Cu} \mathrm{K} \alpha$ radiation $(\lambda=1.5418 \AA)$ with a step size of $0.02^{\circ}$ at a scanning rate of $2\left(^{\circ}\right) / \mathrm{min}$. The final elemental composition was examined by inductively coupled plasma optical emission spectroscopy (ICP-OES; Agilent 5800, USA). To obtain the lattice parameter, Rietveld refinement was performed using the total pattern solution software (TOPAS; Bruker Corp., Karlsruhe, Germany). The microstructure of as-prepared $\mathrm{HE} \mathrm{TMB}_{2}$ powders was investigated by a scanning electron microscope (SEM; Apollo 300, CamScan, UK) equipped with an energy dispersive spectroscopy system (EDS; Inca X-Max $80 \mathrm{~T}$, Oxford, UK). The particle diameter distributions were analyzed based on the secondary electron images, of which at least 350 particles were counted by Feret's statistical method [65]. The distributions of TM elements were investigated by a (scanning) transmission electron microscope ((S)TEM; JEOL JEM 2100F, 200 kV, Japan) equipped with an $80 \mathrm{~mm}$ silicon drift energy dispersive X-ray spectroscope (EDS) and a high-angle annular dark field (HAADF) detector.

The relative complex permittivity $\left(\varepsilon_{\mathrm{r}}=\varepsilon^{\prime}+\mathrm{j} \varepsilon^{\prime \prime}\right)$ and permeability $\left(\mu_{\mathrm{r}}=\mu^{\prime}+\mathrm{j} \mu^{\prime \prime}\right)$ were determined by a vector network analyzer (Agilent N5244A, USA) using the coaxial method in the frequency range of $1.0-18.0 \mathrm{GHz}$. $\mathrm{HE} \mathrm{TMB}_{2}$ powders and paraffin wax were mixed at a mass ratio of $7: 3$ and compacted into a toroidal shape $\left(\Phi_{\text {out }}=\right.$ $7.00 \mathrm{~mm}, \Phi_{\text {in }}=3.04 \mathrm{~mm}$ ). Based on the transmissionline theory and metal back-panel model, the RL was determined from the relative complex permittivity and permeability for a given frequency and sample thickness according to the following equations $[4,33]$ :

$$
\begin{gathered}
\operatorname{RL}(\mathrm{dB})=20 \log \left|\left(Z_{\text {in }}-Z_{0}\right) /\left(Z_{\text {in }}+Z_{0}\right)\right| \\
Z_{\text {in }}=Z_{0} \sqrt{\frac{\mu_{\mathrm{r}}}{\varepsilon_{\mathrm{r}}}} \tanh \left(\mathrm{j} \frac{2 \pi f d \sqrt{\mu_{\mathrm{r}} \varepsilon_{\mathrm{r}}}}{c}\right)
\end{gathered}
$$

where $Z_{0}$ represents the impedance of free space, $Z_{\text {in }}$ represents the normalized input characteristic impedance at the interface between atmosphere and absorber, $\mu_{\mathrm{r}}$ is the relative complex permeability, $\varepsilon_{\mathrm{r}}$ is the relative complex permittivity, $f$ is the frequency, $d$ is the thickness of samples, and $c$ is the velocity of light $(3 \times$ $\left.10^{8} \mathrm{~m} / \mathrm{s}\right)$. The EAB is defined by the frequency range over which the RL value is smaller than $-10 \mathrm{~dB}$, which is comparable to $90 \%$ microwave energy absorption [33].

\section{Results and discussion}

The $\mathrm{AlB}_{2}$-type structure is shown in Fig. 1, which is designated as $C 32$ with the space group of $P 6 / \mathrm{mmm}$ (No. 191) [41]. In this crystal structure, the graphitelike boron layers alternate with the closed packed metal layers, forming a quasi-layered structure.

\section{1 Electronic structure and magnetic properties of $\mathrm{TMB}_{2}(\mathrm{TM}=\mathrm{Ti}, \mathrm{Zr}, \mathrm{Hf}, \mathrm{Nb}, \mathrm{Ta}, \mathrm{Cr}$ )}

As a result of charge transferring and interactions between TM and B atoms, TM-B bonding is ioniccovalent. To determine the ionicity of TM-B bonding, Table 2 summaries the results of Mulliken population analysis. All calculations are based on a consistent atomic basis set to yield Mulliken charge and overlap population for qualitative comparison, whose reliabilities are ensured by spilling parameters in the order of $10^{-3}$ or less. Relatively larger Mulliken charge and relatively smaller overlap population indicate a larger ionic degree of TM-B bonding $[61,62]$. Therefore, the ionicity of $\mathrm{TMB}_{2}$ shows a decreasing tendency with the increased number of electronic shell and valence electron, i.e., the ionic binding ability decreases from $3 d$ to $5 d \mathrm{TMB}_{2}$

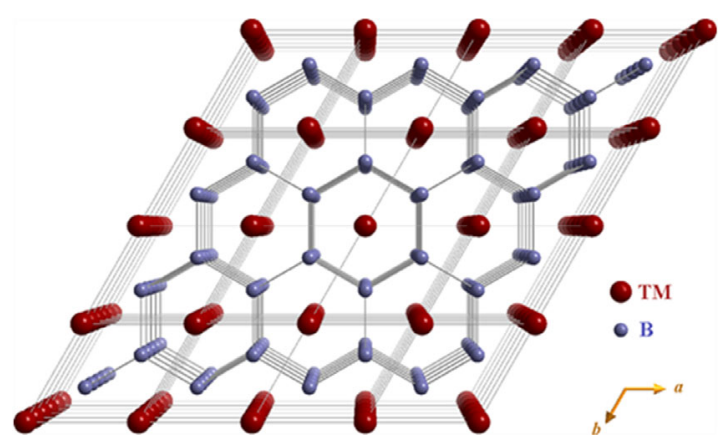

Fig. 1 Crystal structure of $\mathrm{TMB}_{2}$, wherein alternating sheets of TM atoms (dark red) and boron atoms (gray blue) form a quasi-layered structure.

Table 2 Spilling parameters, Mulliken charge, and overlap populations (TM-B bond population and B-B bond population) calculated by Mulliken population analysis

\begin{tabular}{ccccc}
\hline $\mathrm{TMB}_{2}$ & $\begin{array}{c}\text { Spilling } \\
\text { parameter }\end{array}$ & $\begin{array}{c}\text { Cation charge } \\
(|e|)\end{array}$ & $\begin{array}{c}\text { TM-B bond } \\
\text { population }\end{array}$ & $\begin{array}{c}\text { B-B bond } \\
\text { population }\end{array}$ \\
\hline $\mathrm{TiB}_{2}$ & $1.2 \times 10^{-3}$ & 1.10 & 0.12 & 2.39 \\
$\mathrm{ZrB}_{2}$ & $1.1 \times 10^{-3}$ & 1.14 & 0.15 & 2.40 \\
$\mathrm{HfB}_{2}$ & $5.0 \times 10^{-4}$ & 1.05 & 0.38 & 2.24 \\
$\mathrm{NbB}_{2}$ & $1.5 \times 10^{-3}$ & 1.00 & 0.19 & 2.27 \\
$\mathrm{TaB}_{2}$ & $9.0 \times 10^{-4}$ & 0.99 & 0.32 & 2.09 \\
$\mathrm{CrB}_{2}$ & $1.0 \times 10^{-3}$ & 0.91 & 0.14 & 1.71 \\
\hline
\end{tabular}


and weakens with increasing valence electrons, which is derived from the enhanced hybridization between TM $d$ and $\mathrm{B} p$ electrons $[30,31,66]$. Therefore, it is expected that $\mathrm{TiB}_{2}$ possesses the highest degree of ionicity among the group of $\mathrm{TMB}_{2}$.

Spin-polarized calculations were performed to investigate the magnetic properties [63]. Figures 2(a) and 2(b) show the energy band and spin density of states of $\mathrm{CrB}_{2}$, respectively, in which energy splitting and partially polarized spins are observed. The elimination of degeneracy in spin-up $(\alpha)$ and spindown $(\beta)$ eigenstates especially in the vicinity of Fermi states accounts for the high Pauli spin susceptibility, which is due to the reorientation of high energy electrons with reverse spin direction as a respond to the external magnetic field [67]. According to the magnetic susceptibility calculation by Grechnev et al. [42], $\mathrm{CrB}_{2}$ exhibits the largest magnetic susceptibility among group 4 to group $6 \mathrm{TMB}_{2}$, to which Pauli spin susceptibility makes almost the fully contribution. Apart from the existence of partially polarized spins, the $\mathrm{Cr} d$-orbital splitting due to crystal field effect could also result in different energy states. As shown in Figs. 2(c) and 2(d), the splitting of $d$ orbitals leads to lower energy $\mathrm{Cr} e_{\mathrm{g}}$ orbitals and high energy $\mathrm{Cr} t_{2 \mathrm{~g}}$ orbital, which is opposite to the energy splitting scenarios of transition metal carbides due to divergent ligand environment [47]. Therefore, incorporating $\mathrm{CrB}_{2}$ into $\mathrm{HE} \mathrm{TMB}_{2}$ is expected to exhibit high permeability due to the high magnetic susceptibility and the $d$-orbital splitting.
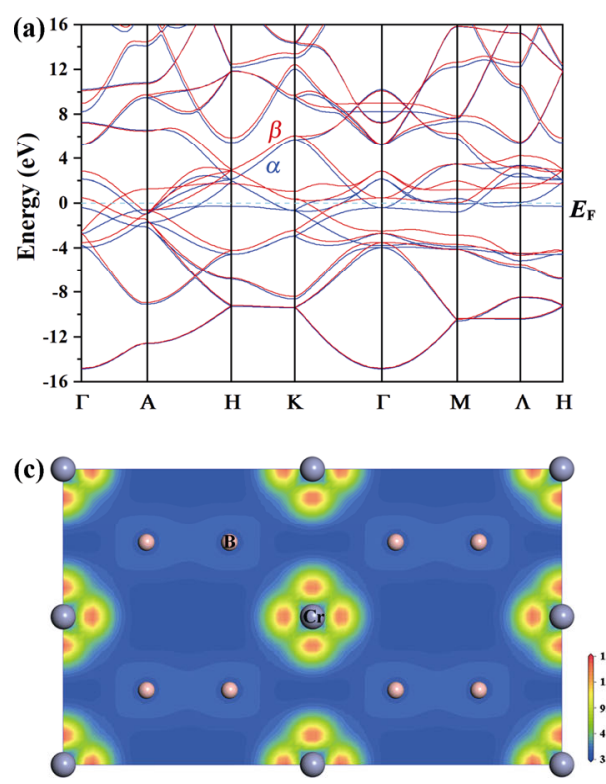

(b)

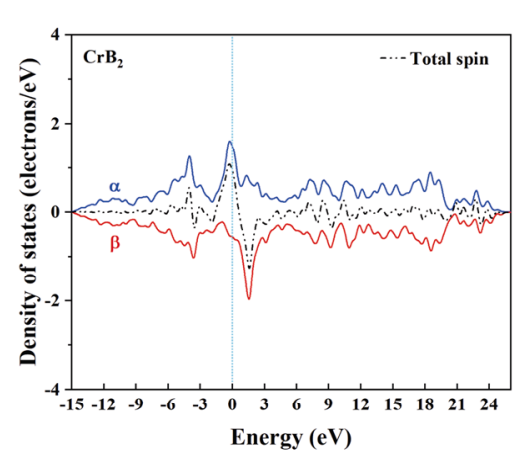

(d)

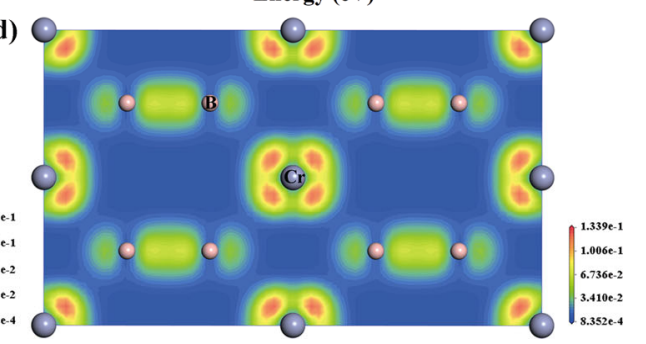

Unlike $\mathrm{CrB}_{2}, \mathrm{TMB}_{2}(\mathrm{TM}=\mathrm{Ti}, \mathrm{Zr}, \mathrm{Hf}, \mathrm{Nb}, \mathrm{Ta})$ without non-full $d$ subshell exhibit no spin polarized phenomenon, while $d$-orbital splitting effects are commonly observed. Representative band structure and partial density of states of $\mathrm{TiB}_{2}$ are displayed in Figs. 3(a) and 3(b). The density of states near Fermi level is contributed by Ti $3 d$ and $\mathrm{B} 2 p$, which endows $\mathrm{TiB}_{2}$ good electrical conductivity. The charge density near Fermi level in Fig. 3(c) shows Ti $3 d\left(e_{\mathrm{g}}\right)$ orbitals, while that with higher energy in Fig. 3(d) exhibits Ti $3 d\left(t_{2 \mathrm{~g}}\right)$ orbitals. Under the external magnetic field, the energy level transition between $\mathrm{Ti} 3 d\left(e_{\mathrm{g}}\right)$ and $\mathrm{Ti}$ $3 d\left(t_{2 \mathrm{~g}}\right)$ might lead to magnetic loss.

As shown in Fig. 4, $\mathrm{TiB}_{2}$ without unpaired electrons exhibits no spin polarization. To investigate the effects of the incorporation of $\mathrm{CrB}_{2}$ into $\mathrm{TiB}_{2}$, spin-polarized calculations were performed on $\left(\mathrm{Ti}_{1-x} \mathrm{Cr}_{x}\right) \mathrm{B}_{2}(x=0$, $0.25,0.5,0.75)$ solid solutions, where $2 \times 2 \times 1$ supercells were used. Notably, the total spin density of states of $\mathrm{TiB}_{2}, \quad\left(\mathrm{Ti}_{0.75} \mathrm{Cr}_{0.25}\right) \mathrm{B}_{2}, \quad\left(\mathrm{Ti}_{0.5} \mathrm{Cr}_{0.5}\right) \mathrm{B}_{2}$, and $\left(\mathrm{Ti}_{0.25} \mathrm{Cr}_{0.75}\right) \mathrm{B}_{2}$ at Fermi level are 0, 0.58, 0.43, and 2.21 , respectively, indicating that the introduction of $\mathrm{CrB}_{2}$ will spur partial spin polarization and magnetic susceptibility. Similar results were obtained when $\mathrm{CrB}_{2}$ was introduced into other $\mathrm{TMB}_{2}(\mathrm{TM}=\mathrm{Zr}, \mathrm{Hf}, \mathrm{Nb}, \mathrm{Ta})$. Therefore, incorporating magnetic $\mathrm{CrB}_{2}$ into $\mathrm{HE} \mathrm{TMB}_{2}$ is meaningful for tuning the EM parameters, i.e., decreasing the electrical conductivity and increasing the magnetic loss capability in the meantime, thus leading to better impedance match and excellent EM wave absorption performance.

Fig. 2 (a) Electronic structure and (b) spin density of states of $\mathrm{CrB}_{2}$; (c) low energy $e_{\mathrm{g}}$ and (d) high energy $t_{2 \mathrm{~g}}$ levels. 

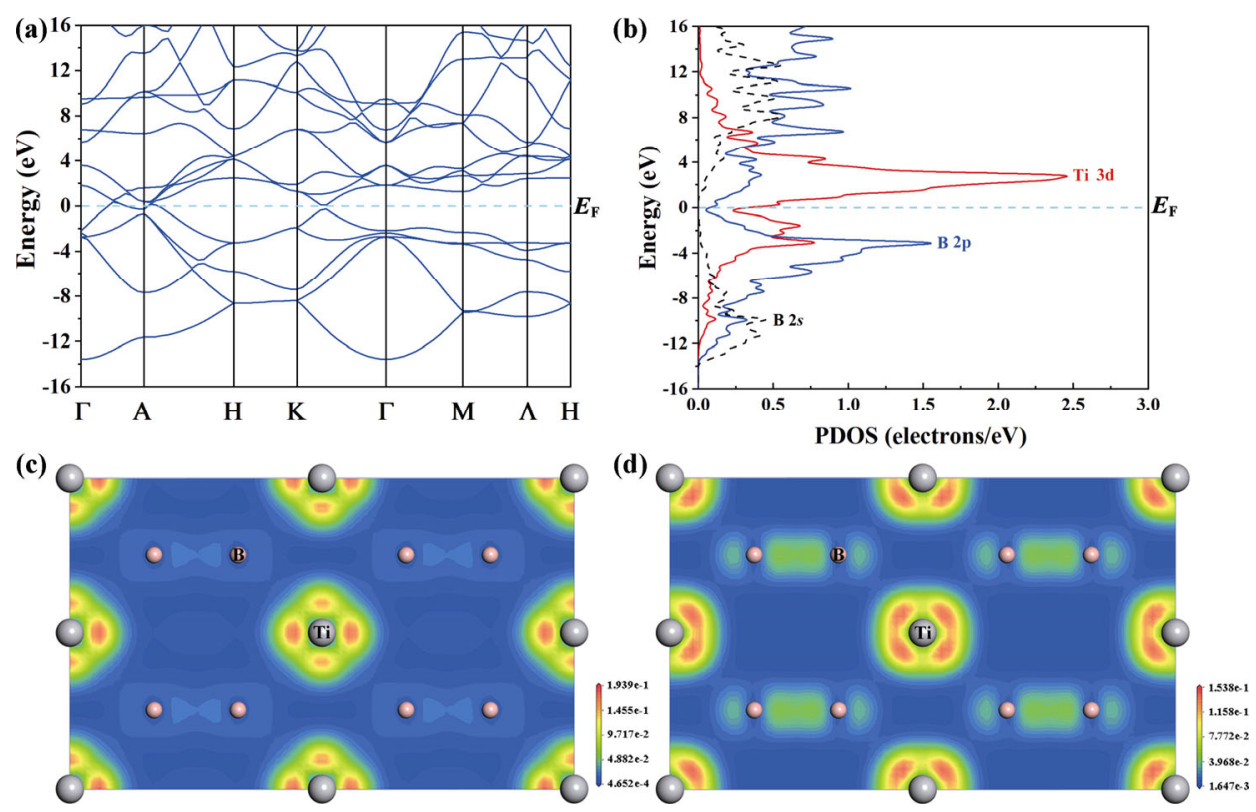

Fig. 3 (a) Electronic structure and (b) partial density of states of $\mathrm{TiB}_{2}$; (c) low energy $e_{\mathrm{g}}$ and (d) high energy $t_{2 \mathrm{~g}}$ levels.
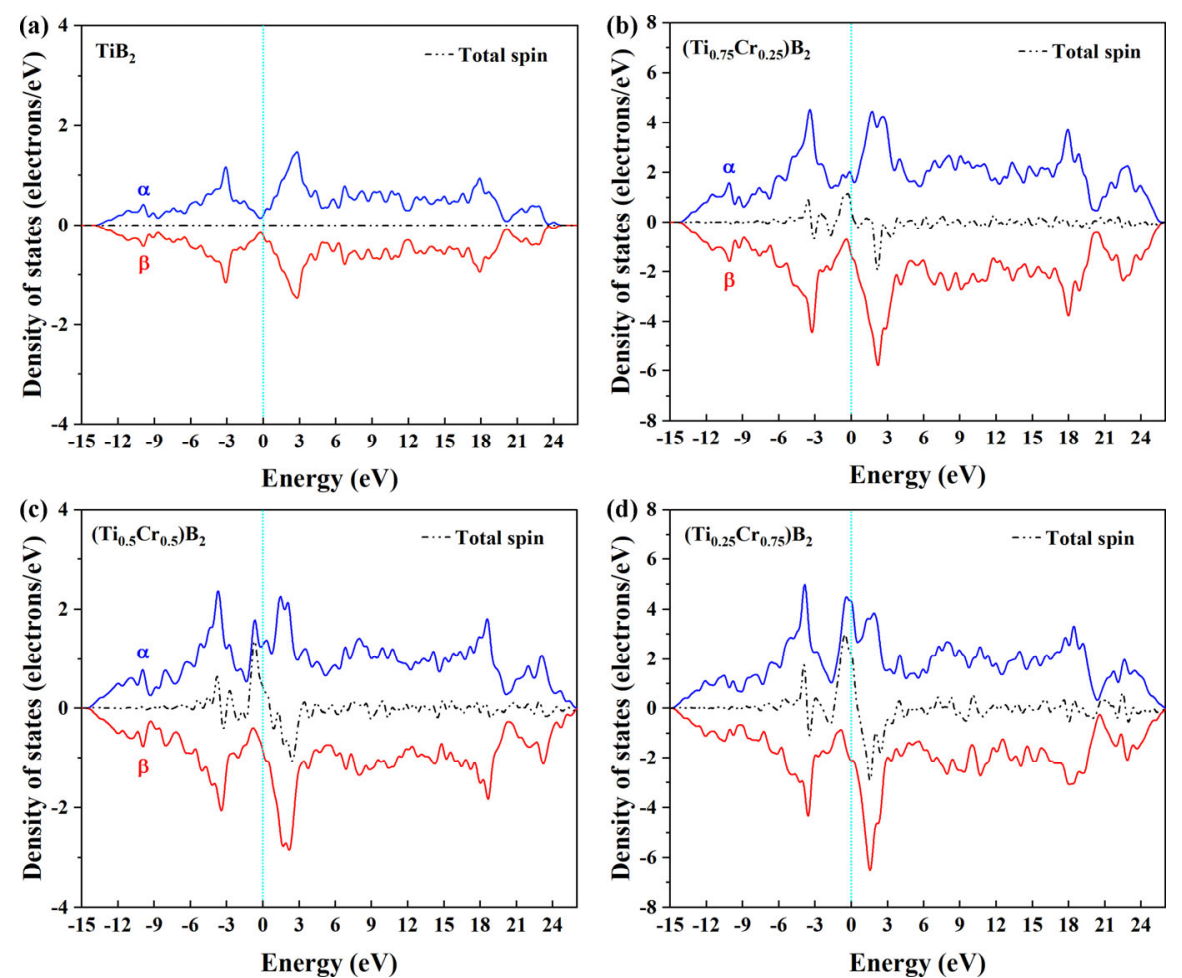

Fig. 4 Spin density of states of (a) $\mathrm{TiB}_{2}$, (b) $\left(\mathrm{Ti}_{0.75} \mathrm{Cr}_{0.25}\right) \mathrm{B}_{2}$, (c) $\left(\mathrm{Ti}_{0.5} \mathrm{Cr}_{0.5}\right) \mathrm{B}_{2}$, and (d) $\left(\mathrm{Ti}_{0.25} \mathrm{Cr}_{0.75}\right) \mathrm{B}_{2}$, where $2 \times 2 \times 1$ supercells were used.

\section{2 Synthesis and characterization of $\mathrm{HE} \mathrm{TMB}_{2}$ powders}

From Fig. 5, the XRD patterns of three as-synthesized $\mathrm{HE} \mathrm{TMB}_{2} \mathrm{~S}$ reveal that the main reflection peaks are indexed as $\mathrm{AlB}_{2}$-type phase, indicating that the $\mathrm{HE}$ $\mathrm{TMB}_{2}$ with multi-principal TM elements were formed after synthesized at $1950{ }^{\circ} \mathrm{C}$ for $1 \mathrm{~h}$. Minor impurities including unsolved $\mathrm{AlB}_{2}$-type $\mathrm{TMB}_{2}(\mathrm{TM}=\mathrm{Zr}, \mathrm{Hf})$ and $\mathrm{Ta}_{3} \mathrm{~B}_{4}$-type orthorhombic $\mathrm{TM}_{3} \mathrm{~B}_{4}$ solid solutions are also detected in $\mathrm{HE} \mathrm{TMB}_{2}-1(\mathrm{TM}=\mathrm{Zr}, \mathrm{Hf}, \mathrm{Nb}, \mathrm{Ta})$ and $\mathrm{HE} \mathrm{TMB}_{2}-2(\mathrm{TM}=\mathrm{Ti}, \mathrm{Zr}, \mathrm{Hf}, \mathrm{Nb}, \mathrm{Ta})$. In specific, minor peaks assigned to the (001) and (101) planes are indexed as $\mathrm{TMB}_{2}(\mathrm{TM}=\mathrm{Zr}$, Hf), indicating that the 


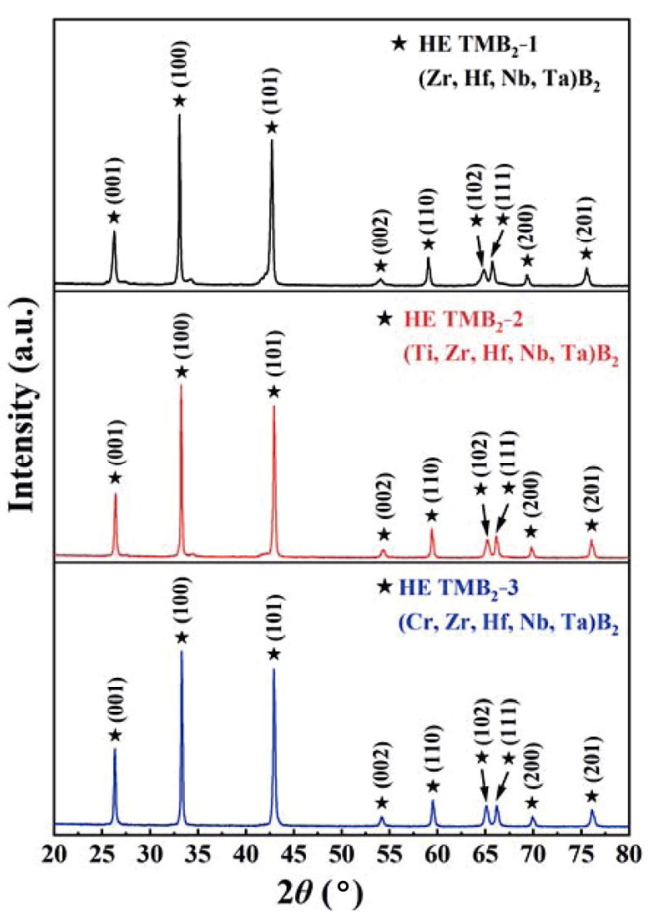

Fig. $5 \mathrm{XRD}$ patterns of $\mathrm{HE} \mathrm{TMB}_{2}-1(\mathrm{TM}=\mathrm{Zr}, \mathrm{Hf}, \mathrm{Nb}$, $\mathrm{Ta}), \mathrm{HE} \mathrm{TMB}_{2}-2(\mathrm{TM}=\mathrm{Ti}, \mathrm{Zr}, \mathrm{Hf}, \mathrm{Nb}, \mathrm{Ta})$, and $\mathrm{HE}$ $\mathrm{TMB}_{2}-3(\mathrm{TM}=\mathrm{Cr}, \mathrm{Zr}, \mathrm{Hf}, \mathrm{Nb}, \mathrm{Ta})$ synthesized at $1950{ }^{\circ} \mathrm{C}$ for dwelling time of $1 \mathrm{~h}$.

formation of solid solution is a multi-step procedure due to the different mutual diffusivity of TM elements. From the thermodynamic perspective, the favorable temperature for synthesizing $\mathrm{TMB}_{2}$ according to Reactions (1)-(3) increases in an order of $\mathrm{TaB}_{2}, \mathrm{NbB}_{2}$, $\mathrm{TiB}_{2}, \mathrm{ZrB}$, and $\mathrm{HfB}_{2}$ [64]. Therefore, the deferred reductions of $\mathrm{ZrO}_{2}$ and $\mathrm{HfO}_{2}$ are responsible for the insufficient solid solution formation. Besides, the presence of $\mathrm{TM}_{3} \mathrm{~B}_{4}$ solid solution phases indexed in the vicinity of (100) peak is mainly attributed to two factors, namely, the accelerated volatilization of boron oxide at high temperature and good thermodynamic stability of $\mathrm{TM}_{3} \mathrm{~B}_{4}(\mathrm{TM}=\mathrm{Ti}, \mathrm{Nb}, \mathrm{Ta})$ [68]. Compared with the synthesis results conducted by $\mathrm{Gu}$ et al. [64], the evaporation of boron oxides at $1950{ }^{\circ} \mathrm{C}$ is more severe, leading to the insufficient boron source. The presence of minor impurities has no detrimental effects on the EM absorption performance [48]. Notably, only $\mathrm{AlB}_{2}$-type reflections can be detected in as-synthesized $\mathrm{HE} \mathrm{TMB}_{2}-3(\mathrm{TM}=\mathrm{Cr}, \mathrm{Zr}, \mathrm{Hf}, \mathrm{Nb}, \mathrm{Ta})$, which is structurally ordered but compositionally disordered with multi-principal TM elements. As shown in Fig. 6, the peak positions of $\mathrm{HE} \mathrm{TMB}_{2}-3$ are lying in the middle of those of single components $\mathrm{TMB}_{2}(\mathrm{TM}=\mathrm{Zr}$, $\mathrm{Hf}, \mathrm{Nb}, \mathrm{Ta}$ ), while keeping a distance from those of

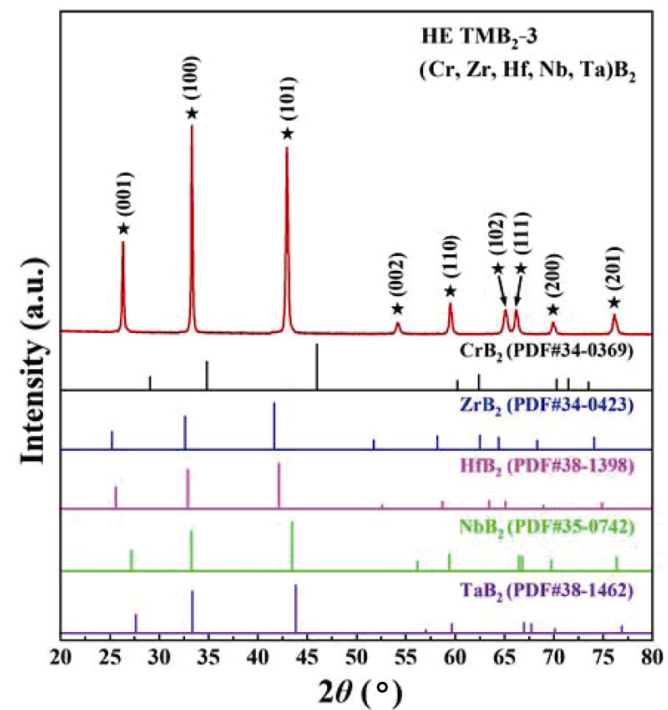

Fig. $6 \mathrm{XRD}$ patterns of $\mathrm{HE} \mathrm{TMB}_{2}-3(\mathrm{TM}=\mathrm{Cr}$, Zr, Hf, $\mathrm{Nb}$, Ta) powders together with those of $\mathrm{CrB}_{2}, \mathrm{ZrB}_{2}, \mathrm{HfB}_{2}$, $\mathrm{NbB}_{2}$, and $\mathrm{TaB}_{2}$ obtained from ICDD/JCPDS cards.

$\mathrm{CrB}_{2}$, which could be ascribed to the limited solid solution quantity of $\mathrm{CrB}_{2}$ with relatively smaller lattice parameters.

The final compositions of multi-principal TM elements are of significance for the EM wave absorption performance. Table 3 compares the nominal equimolar compositions and the elemental compositions analyzed by ICP-OES. The elemental proportions of TM cations examined by ICP-OES in $\mathrm{HE} \mathrm{TMB}_{2}-1$ and $\mathrm{HE} \mathrm{TMB}_{2}-2$ are close to equimolar, while the atomic content of $\mathrm{Cr}$ is lower than those of the other TM elements in HE $\mathrm{TMB}_{2}-3$, which is responsible for the offset of the reflection peaks in Fig. 6. Therefore, combining XRD and ICP-OES analyses, the final composition of $\mathrm{HE} \mathrm{TMB}_{2}-3$ is determined as $\left(\mathrm{Cr}_{0.139} \mathrm{Zr}_{0.210} \mathrm{Hf}_{0.219} \mathrm{Nb}_{0.216} \mathrm{Ta}_{0.216}\right) \mathrm{B}_{2}$. Since the volatility of $\mathrm{Cr}_{2} \mathrm{O}_{3}$ under vacuum condition has at least three orders of magnitude greater than those of other $\mathrm{TM}$ oxides $(\mathrm{TM}=\mathrm{Zr}, \mathrm{Hf}, \mathrm{Nb}, \mathrm{Ta}$ ) used as reactants, the limited solid solution quantity of $\mathrm{CrB}_{2}$ in $\mathrm{HE} \mathrm{TMB}_{2}-3$ could be ascribed to the evaporation of

Table 3 Nominal compositions and measured elemental compositions of TM in as-synthesized $\mathrm{HE}$ $\mathrm{TMB}_{2}-1$ (TM $=\mathrm{Zr}$, Hf, Nb, Ta), HE TMB -2 (TM = Ti, $\mathrm{Zr}$, Hf, Nb, Ta), and HE $\mathrm{TMB}_{2}-3$ (TM $=\mathrm{Cr}, \mathrm{Zr}$, Hf, Nb, Ta)

\begin{tabular}{lcc}
\hline HE TMB & Nominal composition & Measured composition \\
\hline $\mathrm{HE} \mathrm{TMB}_{2}-1$ & $\left(\mathrm{Zr}_{0.25} \mathrm{Hf}_{0.25} \mathrm{Nb}_{0.25} \mathrm{Ta}_{0.25}\right) \mathrm{B}_{2}$ & $\left(\mathrm{Zr}_{0.240} \mathrm{Hf}_{0.248} \mathrm{Nb}_{0.258} \mathrm{Ta}_{0.254}\right) \mathrm{B}_{2}$ \\
$\mathrm{HE} \mathrm{TMB}$ & $-2\left(\mathrm{Ti}_{0.2} \mathrm{Zr}_{0.2} \mathrm{Hf}_{0.2} \mathrm{Nb}_{0.2} \mathrm{Ta}_{0.2}\right) \mathrm{B}_{2}\left(\mathrm{Ti}_{0.187} \mathrm{Zr}_{0.198} \mathrm{Hf}_{0.206} \mathrm{Nb}_{0.204} \mathrm{Ta}_{0.205}\right) \mathrm{B}_{2}$ \\
$\mathrm{HE} \mathrm{TMB}$ & $-3\left(\mathrm{Cr}_{0.2} \mathrm{Zr}_{0.2} \mathrm{Hf}_{0.2} \mathrm{Nb}_{0.2} \mathrm{Ta}_{0.2}\right) \mathrm{B}_{2}\left(\mathrm{Cr}_{0.133} \mathrm{Zr}_{0.210} \mathrm{Hf}_{0.219} \mathrm{Nb}_{0.216} \mathrm{Ta}_{0.216}\right) \mathrm{B}_{2}$ \\
\hline
\end{tabular}


$\mathrm{Cr}_{2} \mathrm{O}_{3}$ with increasing temperature, which is in turn beneficial to boosting the mass transferring [69].

Based on the ICP-OES results, the average lattice parameters $(\bar{a}, \bar{c})$ of $\mathrm{HE} \mathrm{TMB}_{2} \mathrm{~s}$ are calculated using the data of $\mathrm{TMB}_{2} \mathrm{~s}$ derived from the standard ICDD/ JCPDS cards. The lattice parameters $(a, c)$ of as-prepared $\mathrm{HE} \mathrm{TMB}_{2} \mathrm{~S}$ were determined by Rietveld refinement using TOPAS software. The theoretical density $(\rho)$ was calculated from the refined lattice parameters and the atomic mass according to the ICP-OES results. Table 4 summaries the refined lattice parameters $(a, c)$, the average lattice parameters $(\bar{a}, \bar{c})$, and the theoretical density $(\rho)$ together with the reliability factors $\left(R_{\mathrm{p}}, R_{\mathrm{wp}}\right)$. The lattice parameters of $\mathrm{HE} \mathrm{TMB}_{2} \mathrm{~s}$ are close to the average ones, while relatively large deviations of the refined lattice parameters from the average ones $(\Delta a=$ $0.16 \%, \Delta c=1.46 \%)$ are identified in $\mathrm{HE} \mathrm{TMB}_{2}-3$.

Figures 7(a)-7(c) display representative SEM analyses of as-synthesized $\mathrm{HE} \mathrm{TMB}_{2}$ powders. Under different growth conditions, plate-like and column-like particles with residue growth steps are commonly observed [70].
Figures 7(d)-7(f) display the particle size distribution of as-synthesized $\mathrm{HE} \mathrm{TMB}_{2}$ powders, where $\mathrm{HE}$ $\mathrm{TMB}_{2}-3$ exhibits wide distribution range from 0.5 to $4.2 \mu \mathrm{m}$. The average particle size of $\mathrm{HE} \mathrm{TMB}_{2}-1$ and $\mathrm{HE} \mathrm{TMB}_{2}-2$ are 0.83 and $0.78 \mu \mathrm{m}$, respectively, while that of $\mathrm{HE} \mathrm{TMB}_{2}-3$ reaches $2.2 \mu \mathrm{m}$. The as-synthesized $\mathrm{HE} \mathrm{TMB}_{2}-1$ and $\mathrm{HE} \mathrm{TMB}_{2}-2$ with relatively smaller particle size of 0.83 and $0.78 \mu \mathrm{m}$ are expected to exhibit stronger interfacial polarization, which is helpful to boost the dielectric loss.

To characterize the distribution of different TM elements, a representative STEM-EDS analysis of HE $\mathrm{TMB}_{2}-3(\mathrm{TM}=\mathrm{Cr}, \mathrm{Zr}, \mathrm{Hf}, \mathrm{Nb}, \mathrm{Ta})$ is shown in Fig. 8 . Homogeneous elemental distributions of TM cations both in the grain interior (Fig. 8(a)) and the grain boundary (Fig. 8(b)) are verified by EDS elemental mappings. Combining the XRD and STEM-EDS analyses, it can be concluded that single phase $\left(\mathrm{Cr}_{0.139} \mathrm{Zr}_{0.210} \mathrm{Hf}_{0.219} \mathrm{Nb}_{0.216} \mathrm{Ta}_{0.216}\right) \mathrm{B}_{2} \quad\left(\mathrm{HE} \quad \mathrm{TMB}_{2}-3\right)$ powders with a homogeneous elemental distribution are synthesized.

Table 4 Refined lattice parameters $(a, c)$, average lattice parameters $(\bar{a}, \bar{c})$ from corresponding single component phases obtained from standard ICDD/JCPDS cards, and calculated theoretical density $(\rho)$ together with reliability factors $\left(R_{\mathrm{p}}\right.$ and $R_{\mathrm{wp}}$ ) of as-synthesized $\mathrm{HE} \mathrm{TMB}_{2} \mathrm{~S}$

\begin{tabular}{|c|c|c|c|c|c|c|c|}
\hline $\mathrm{HE} \mathrm{TMB}_{2}$ & $a(\AA)$ & $\bar{a}(\AA)$ & $c(\AA)$ & $\bar{c}(\AA)$ & $\rho\left(\mathrm{g} / \mathrm{cm}^{3}\right)$ & $R_{\mathrm{p}}(\%)$ & $R_{\mathrm{wp}}(\%)$ \\
\hline $\mathrm{HE} \mathrm{TMB}_{2}-1$ & 3.1267 & 3.1295 & 3.3950 & 3.3737 & 9.110 & 11.87 & 15.92 \\
\hline $\mathrm{HE} \mathrm{TMB}_{2}-2$ & 3.1065 & 3.1113 & 3.3738 & 3.3473 & 8.335 & 9.10 & 12.30 \\
\hline $\mathrm{HE} \mathrm{TMB}_{2}-3$ & 3.1031 & 3.1081 & 3.3825 & 3.3337 & 8.610 & 8.37 & 11.23 \\
\hline
\end{tabular}
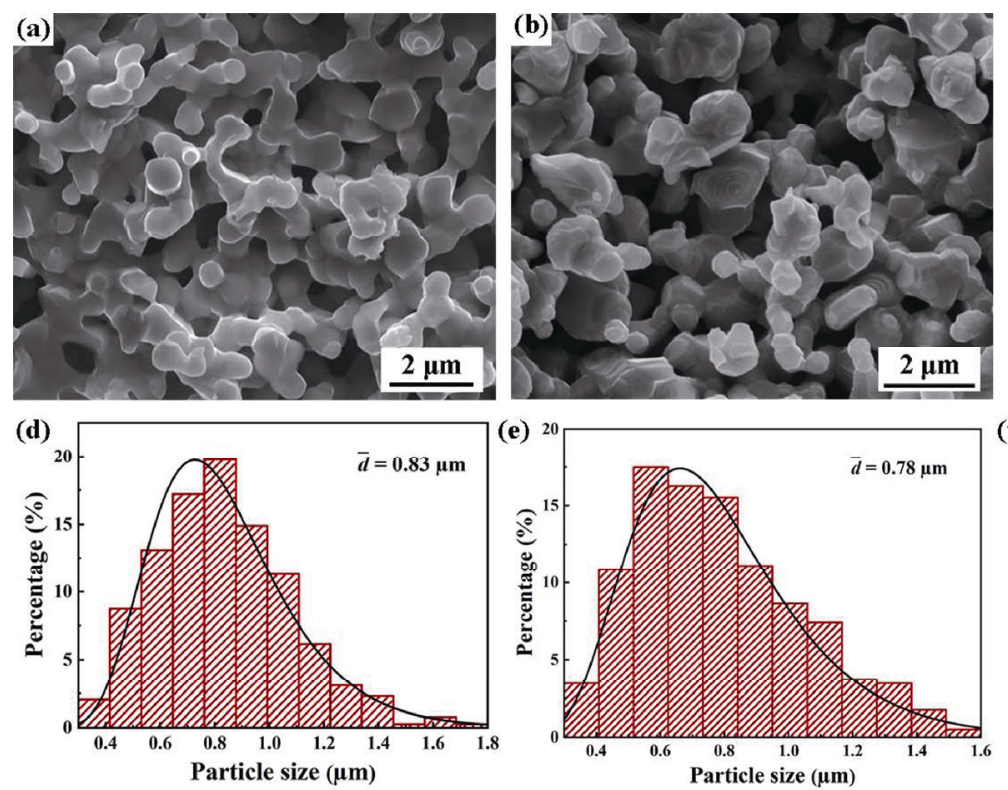
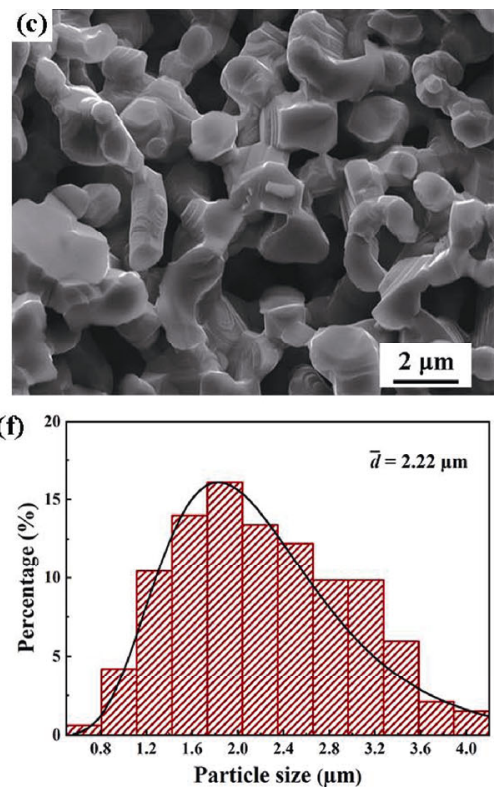

Fig. 7 SEM images and particle distributions of (a, d) HE TMB ${ }_{2}-1(\mathrm{TM}=\mathrm{Zr}, \mathrm{Hf}, \mathrm{Nb}, \mathrm{Ta}),(\mathrm{b}, \mathrm{e}) \mathrm{HE} \mathrm{TMB} \mathrm{H}_{2}-2(\mathrm{TM}=\mathrm{Ti}, \mathrm{Zr}, \mathrm{Hf}$, $\mathrm{Nb}, \mathrm{Ta})$, and (c, f) $\mathrm{HE} \mathrm{TMB}_{2}-3(\mathrm{TM}=\mathrm{Cr}, \mathrm{Zr}, \mathrm{Hf}, \mathrm{Nb}, \mathrm{Ta})$ powders synthesized at $1950{ }^{\circ} \mathrm{C}$ for the dwelling time of $1 \mathrm{~h}$. 


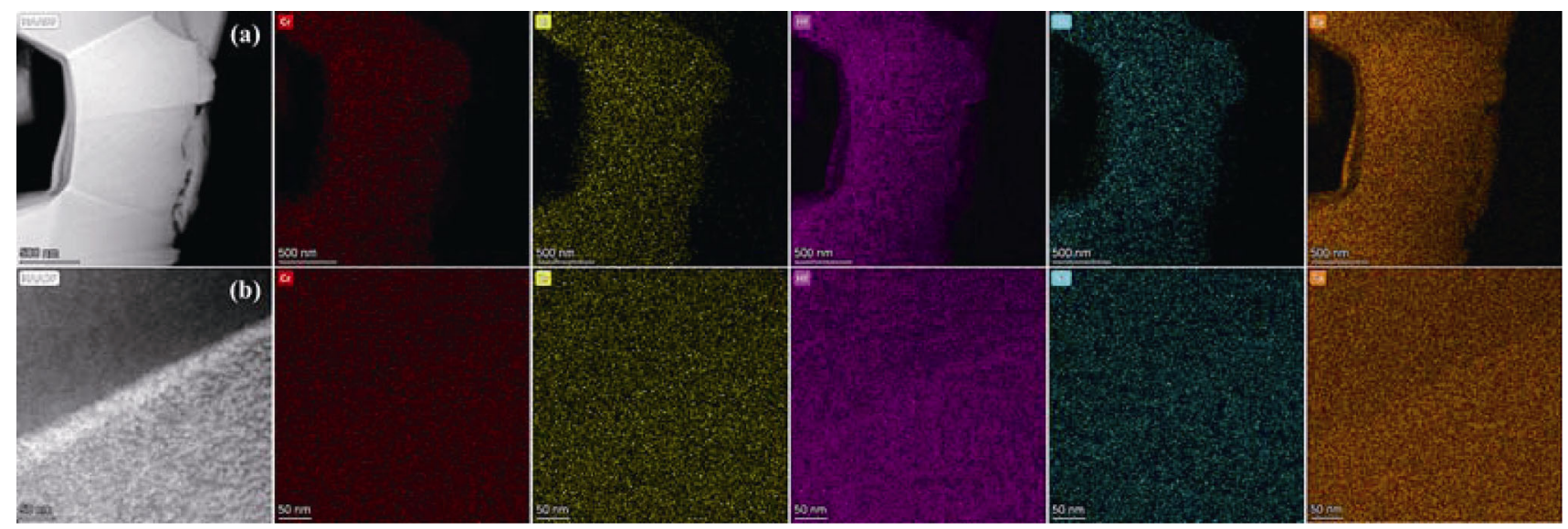

Fig. 8 Representative STEM images in (a) the grain interior and (b) the grain boundary and the corresponding EDS elemental mappings.

\section{3 Electromagnetic properties of $\mathrm{HE} \mathrm{TMB}_{2}$ powders}

Generally, the dissipations of EM wave energy can be conducted by electronic and/or magnetic interactions between microwave absorbers and alternating EM wave field. Therefore, complex permittivity $\left(\varepsilon_{\mathrm{r}}=\varepsilon^{\prime}+\right.$ $\left.\mathrm{j} \varepsilon^{\prime \prime}\right)$ and complex permeability $\left(\mu_{\mathrm{r}}=\mu^{\prime}+\mathrm{j} \mu^{\prime \prime}\right)$ are two critical factors determining the EM wave absorption performance, of which the real parts $\left(\varepsilon^{\prime}\right.$ and $\left.\mu^{\prime}\right)$ and the imaginary parts $\left(\varepsilon^{\prime \prime}\right.$ and $\left.\mu^{\prime \prime}\right)$ represent the storage and loss capabilities of EM wave energy, respectively [33].

To assess the EM wave absorption performance of as-synthesized $\mathrm{HE} \mathrm{TMB}_{2}$ powders, the frequency dependent EM parameters are summarized in Fig. 9. As revealed in Fig. 9(a), the values of $\varepsilon^{\prime}$ decrease with increasing frequency as a phenomenon of dispersion and exhibit distinctions among three $\mathrm{HE} \mathrm{TMB}_{2} \mathrm{~s}$, indicating that the dielectric polarization ability ranks in the following order: $\mathrm{HE} \mathrm{TMB}_{2}-2>\mathrm{HE} \mathrm{TMB}_{2}-1>$ $\mathrm{HE} \mathrm{TMB}_{2}-3$. In essence, the polarizability of dielectric medium is made up of several contributions from electronic polarization, ionic polarization, orientational polarization, and space charge polarization [71]. The relaxation frequencies of electronic and ionic deviation polarizations are in the frequency range of $\mathrm{THz}$ and $\mathrm{PHz}$, respectively, which can keep shifting orientation direction with alternating electric field at $\mathrm{GHz}$ range. However, space charge polarization fails to make contribution due to its low relaxation frequency, while the effect of orientational polarization is reduced with increasing frequency. Therefore, electronic and ionic deviation polarizations play a dominant role in determining the polarizability, while orientational and space charge polarizations contribute to the dielectric loss. As for $\mathrm{TMB}_{2} \mathrm{~s}$, the ionic-covalent TM-B bonding consists of ionic bonding due to charge transferring from TM atom to B atom and covalent bonding from the hybridization between $\mathrm{TM} d$ and $\mathrm{B} p$ electrons. From $3 d$ to $5 d \mathrm{TMB}_{2}$, the TM-B ionic binding ability becomes weaker as is reflected by the reduced Mulliken charge and increased TM-B bond population in Table 2. In this light, Ti-B bonding exhibits the largest degree of ionic bonding and the smallest ionic mass, which is expected to possesses the strongest ionic polarizability. As for electronic polarization, $\mathrm{Ti}$ $3 d$ electrons are strictly localized and possess the strongest Coulomb interaction compared with other delocalized TM $d$ electrons, which reinforces the restoring force and is beneficial to strengthening electronic polarization. Therefore, the incorporation of $\mathrm{TiB}_{2}$ into $\mathrm{HE} \mathrm{TMB}_{2}-2$ is beneficial to strengthening the dielectric storage capability. Figure 9(b) shows the frequency dependence of imaginary permittivity $\left(\varepsilon^{\prime \prime}\right)$, which is mainly derived from polarization relaxation loss and conduction loss, and can be described as [33]:

$$
\varepsilon^{\prime \prime} \approx \varepsilon_{\mathrm{p}}^{\prime \prime}+\varepsilon_{\mathrm{c}}^{\prime \prime}=\left(\varepsilon_{0}-\varepsilon_{\infty}\right) \frac{\omega \tau}{1+\omega^{2} \tau^{2}}+\frac{\sigma}{2 \pi f \varepsilon_{0}}
$$

where $\varepsilon_{\mathrm{p}}^{\prime \prime}$ and $\varepsilon_{\mathrm{c}}^{\prime \prime}$ represent the polarization loss and conduction loss, respectively, $\varepsilon_{0}$ and $\varepsilon_{\infty}$ refer to the permittivity in vacuum and at infinite frequency, respectively, $\omega$ is the angular frequency, $\tau$ is the relaxation time, and $f$ is the frequency. The presence of residue impurities and paraffin wax can spur the interfacial polarizations (called the Maxwell-Wagner effect [72]) and related relaxations in heterogeneous materials, which is related to the specific surface area 
(a)

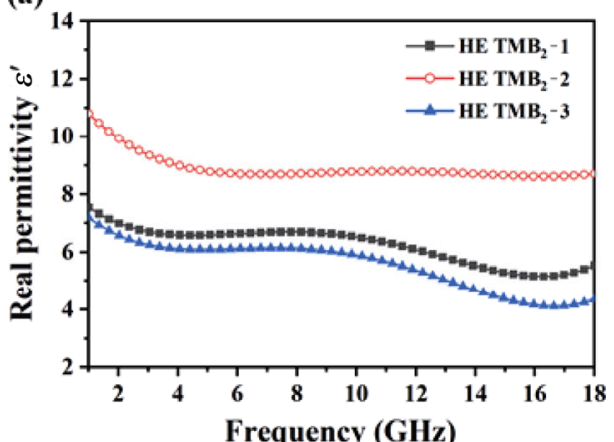

(c)

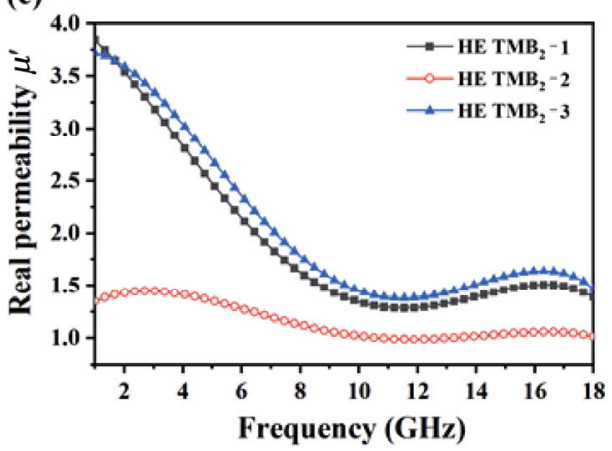

(b)

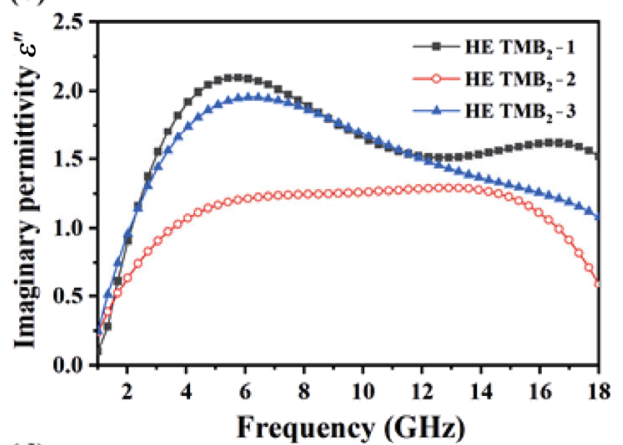

(d)

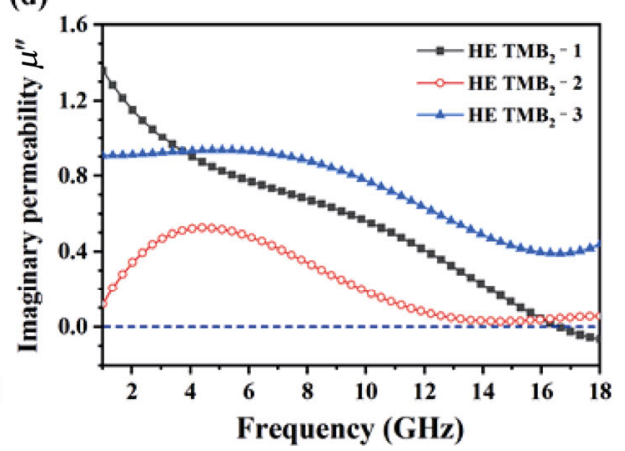

Fig. 9 Electromagnetic parameters of $\mathrm{HE}_{\mathrm{TMB}} \mathrm{s}$ : (a) real permittivity $\left(\varepsilon^{\prime}\right)$, (b) imaginary permittivity $\left(\varepsilon^{\prime \prime}\right)$, (c) real permeability $\left(\mu^{\prime}\right)$, and (d) imaginary permeability $\left(\mu^{\prime \prime}\right)$.

of $\mathrm{HE} \mathrm{TMB}_{2}$ powders. The average particle size of $\mathrm{HE}$ $\mathrm{TMB}_{2}-1$ and $\mathrm{HE} \mathrm{TMB}_{2}-3$ differs by a factor of about 3 . However, their $\varepsilon^{\prime \prime}$ values distinct scarcely, which indicates that there are other dominant pathways to dissipate EM wave energy rather than interfacial polarization loss. According to the free electron theory [33] $\left(\varepsilon_{\mathrm{c}}^{\prime \prime}=\sigma /\left(2 \pi f \varepsilon_{0}\right)\right)$, the reduction of electric conductivity $(\sigma)$ will lead to the reduction of the $\varepsilon^{\prime \prime}$ value. With the increase of disorder in a fixed lattice assessed by configurational entropy $\left(\Delta S_{\text {conf }}\right)$, the electrical conductivity decreases in the order of $\mathrm{HE}$ $\mathrm{TMB}_{2}-1$, $\mathrm{HE} \mathrm{TMB}_{2}-3$, and $\mathrm{HE} \mathrm{TMB}_{2}-2$, which coincides with the decreased magnitude of $\varepsilon^{\prime \prime}$. Therefore, it can be concluded that the conduction loss is the dominant contributor for the dielectric loss. Besides, the formation of solid solution with multi-principal components is expected to introduce a host of defects, which could serve as polarization centers and hinder the re-orientation of dipoles and the rearrangement of space charges in the alternating electric field, thus leading to energy consumption. Therefore, multi-relaxations in $\mathrm{GHz}$ range are responsible for the resonance peaks existing in the $\varepsilon^{\prime \prime}-f$ curves for $\mathrm{HE} \mathrm{TMB}_{2} \mathrm{~s}$.

Generally, the dielectric loss ability can be evaluated by dielectric loss tangent $\left(\tan \delta_{\varepsilon}=\varepsilon^{\prime \prime} / \varepsilon^{\prime}\right)$. As shown in
Fig. 10(a), $\mathrm{HE} \mathrm{TMB}_{2}-1$ and $\mathrm{HE} \mathrm{TMB}_{2}-3$ exhibit similar magnitude of dielectric loss across the testing frequency span, while $\mathrm{HE} \mathrm{TMB}_{2}-2$ possesses relatively lower loss tangent values. As mentioned above, except for conduction loss, polarization relaxation loss also contributes to the dielectric loss, which can be determined by Cole-Cole curves in Fig. 10(c). Due to the unneglectable conductivity and multi-relaxation time existing in $\mathrm{HE} \mathrm{TMB}_{2} \mathrm{~s}$, the skewed semicircles are identified, which represent relaxation progresses [33].

The complex permeability and magnetic loss tangent of $\mathrm{HE} \mathrm{TMB}_{2} \mathrm{~s}$ are shown in Figs. 9(c), 9(d), and 10(b). In Fig. 9(c), the $\mu^{\prime}$ values of $\mathrm{HE} \mathrm{TMB}_{2} \mathrm{~s}$ gradually decrease with increasing frequency due to the relaxations of magnetic moments. Notably, the incorporation of $\mathrm{TiB}_{2}$ in $\mathrm{HE} \mathrm{TMB}_{2}-2$ gives rise to the reduction of $\mu^{\prime}$ values over the testing frequency span compared with $\mathrm{HE} \mathrm{TMB}_{2}-1$, which is related to the diamagnetism induced by the localized Ti $3 d$ electrons $[42,73]$. As for $\mathrm{HE} \mathrm{TMB}_{2}-3$, the antiferromagnetic $\mathrm{CrB}_{2}$ possesses the highest magnetic susceptibility among group 4 to group $6 \mathrm{TMB}_{2} \mathrm{~S}$ due to partially polarized spins, which is critical for the enhancement of magnetic storage capacity [42-44]. In Fig. 9(d), the $\mu^{\prime \prime}$ values of HE $\mathrm{TMB}_{2}-1$ and $\mathrm{HE} \mathrm{TMB}_{2}-3$ exhibit decreasing tendency with frequency, while for $\mathrm{HE} \mathrm{TMB}_{2}-2$, the $\mu^{\prime \prime}$ values increase from 1 to $5 \mathrm{GHz}$ and decrease in the frequency 


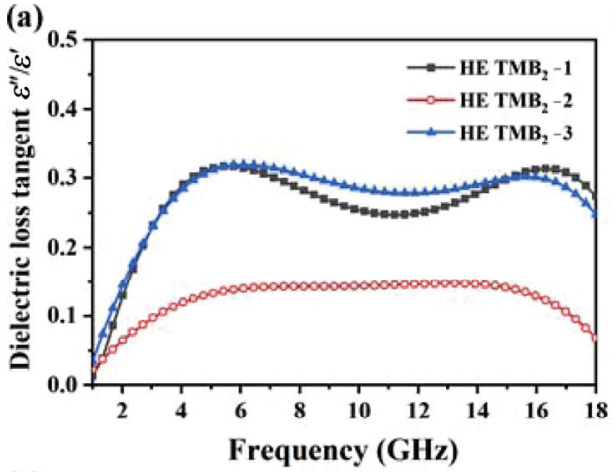

(c)

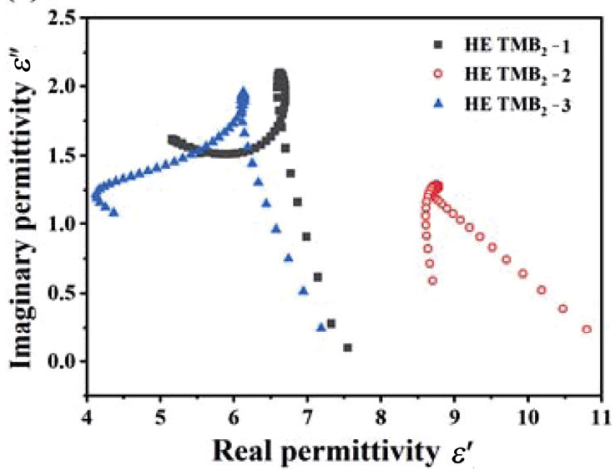

(b)

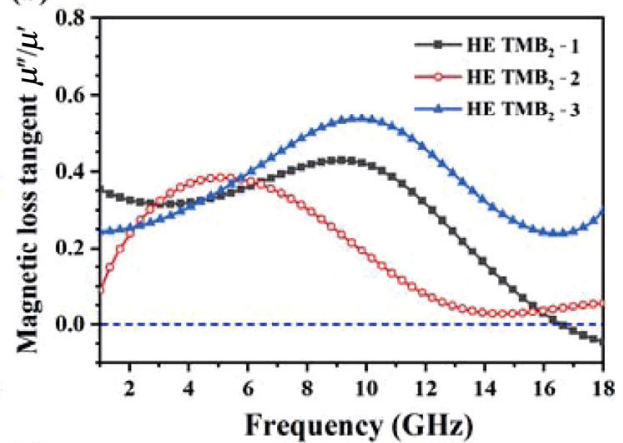

(d)

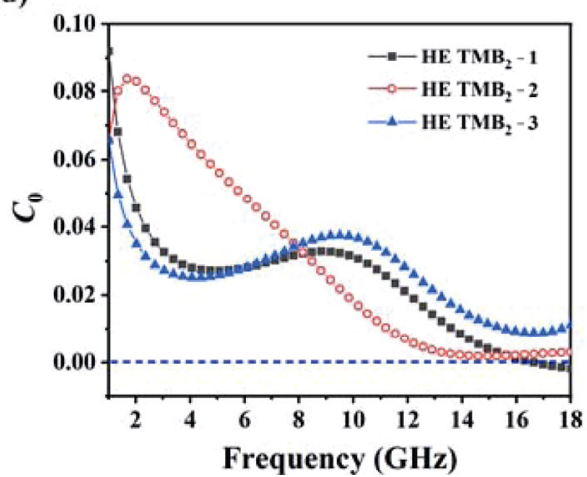

Fig. 10 Frequency dependences of (a) dielectric loss tangent $\left(\varepsilon^{\prime \prime} / \varepsilon^{\prime}\right)$ and (b) magnetic loss tangent ( $\left.\mu^{\prime \prime} / \mu^{\prime}\right)$; (c) Cole-Cole semicircles ( $\varepsilon^{\prime \prime}$ vs. $\left.\varepsilon^{\prime}\right)$ and (d) $C_{0}-f$ curves of $\mathrm{HE} \mathrm{TMB}_{2} \mathrm{~s}$.

range of 5-14 GHz and then keep almost steady above $14 \mathrm{GHz}$. Thus, the incorporation of $\mathrm{TiB}_{2}$ into $\mathrm{HE}$ $\mathrm{TMB}_{2}-2$ can refrain from the skin effect occurred in $\mathrm{HE} \mathrm{TMB}_{2}-1$ and realize better impedance matching at high frequency, as demonstrated by the positive values of $\mu^{\prime \prime}$ in frequency range of $14-18 \mathrm{GHz}[6,7]$. Moreover, the $\mu^{\prime \prime}$ values of $\mathrm{HE} \mathrm{TMB}_{2}-3$ with antiferromagnetic $\mathrm{CrB}_{2}$ remain a high level in the frequency range of $1-18 \mathrm{GHz}$, which is beneficial to high magnetic loss. As is expected, obvious resonance peaks of magnetic loss tangent $\left(\tan \delta_{\mu}=\mu^{\prime \prime} / \mu^{\prime}\right)$ are observed, which could be ascribed to the resonance loss in Fig. 10(b). Under the weak EM filed at $\mathrm{GHz}$ range, the electron paramagnetic resonance frequency is at microwave frequency range, which is expected to cause intense attenuation of EM wave energy [45,46]. Besides, the excitation from different $d$-orbital energy levels as a respond to incident EM wave energy also contributes to resonance loss [47]. Therefore, the resonance loss and eddy current loss are the dominant contributors to the magnetic loss, wherein the eddy current loss is only related to the electrical conductivity $(\sigma)$ of materials and the matching thickness $(d)$, as described by Eq. (7) [33]:

$$
C_{0}=\mu^{\prime \prime}\left(\mu^{\prime}\right)^{-2} f^{-1}=2 \pi \mu_{0} d^{2} \sigma
$$

where $\mu_{0}$ is the vacuum permeability. Supposing that the eddy current loss is the sole reason for the magnetic loss, the value of $C_{0}$ should remain a constant; otherwise, the electron paramagnetic resonance loss is preponderance. As shown in Fig. 10(d), in spite of the unchanged period of the $C_{0}-f$ curve from 14 to $18 \mathrm{GHz}$ for $\mathrm{HE} \mathrm{TMB}_{2}-2$, the $C_{0}$ values of $\mathrm{HE} \mathrm{TMB}_{2} \mathrm{~S}$ exhibit apparent variation with frequency, indicating electron paramagnetic resonances occur in the testing frequency range. From Fig. 10(b), the resonance frequency for $\mathrm{HE} \mathrm{TMB}{ }_{2}-1, \mathrm{HE} \mathrm{TMB}_{2}-2$, and $\mathrm{HE} \mathrm{TMB}_{2}-3$ are 9.2, 5.1, and $9.8 \mathrm{GHz}$, respectively. The occurrences of resonance loss at $\mathrm{GHz}$ range are mainly attributed to the anisotropic magnetic susceptibility, crystal field effects, as well as electron paramagnetic resonance induced by a host of defects in $\mathrm{HE} \mathrm{TMB}_{2} \mathrm{~s}$.

Combining dielectric and magnetic loss tangents, it can be inferred that the synergistic effects of dielectric and magnetic losses are realized in three $\mathrm{HE} \mathrm{TMB}_{2} \mathrm{~S}$, which are expected to display high EM wave absorption performance. Figure 11(a) exhibits the total loss tangent ( $\tan \delta_{\varepsilon}+\tan \delta_{\mu}$ ) of $\mathrm{HE} \mathrm{TMB}_{2} \mathrm{~s}$, indicating that the consumption capacity of EM wave energy could be ranked roughly in the following order: $\mathrm{HE} \mathrm{TMB}_{2}-3>$ $\mathrm{HE} \mathrm{TMB}_{2}-1>\mathrm{HE} \mathrm{TMB}_{2}-2$. Taking the coupling 

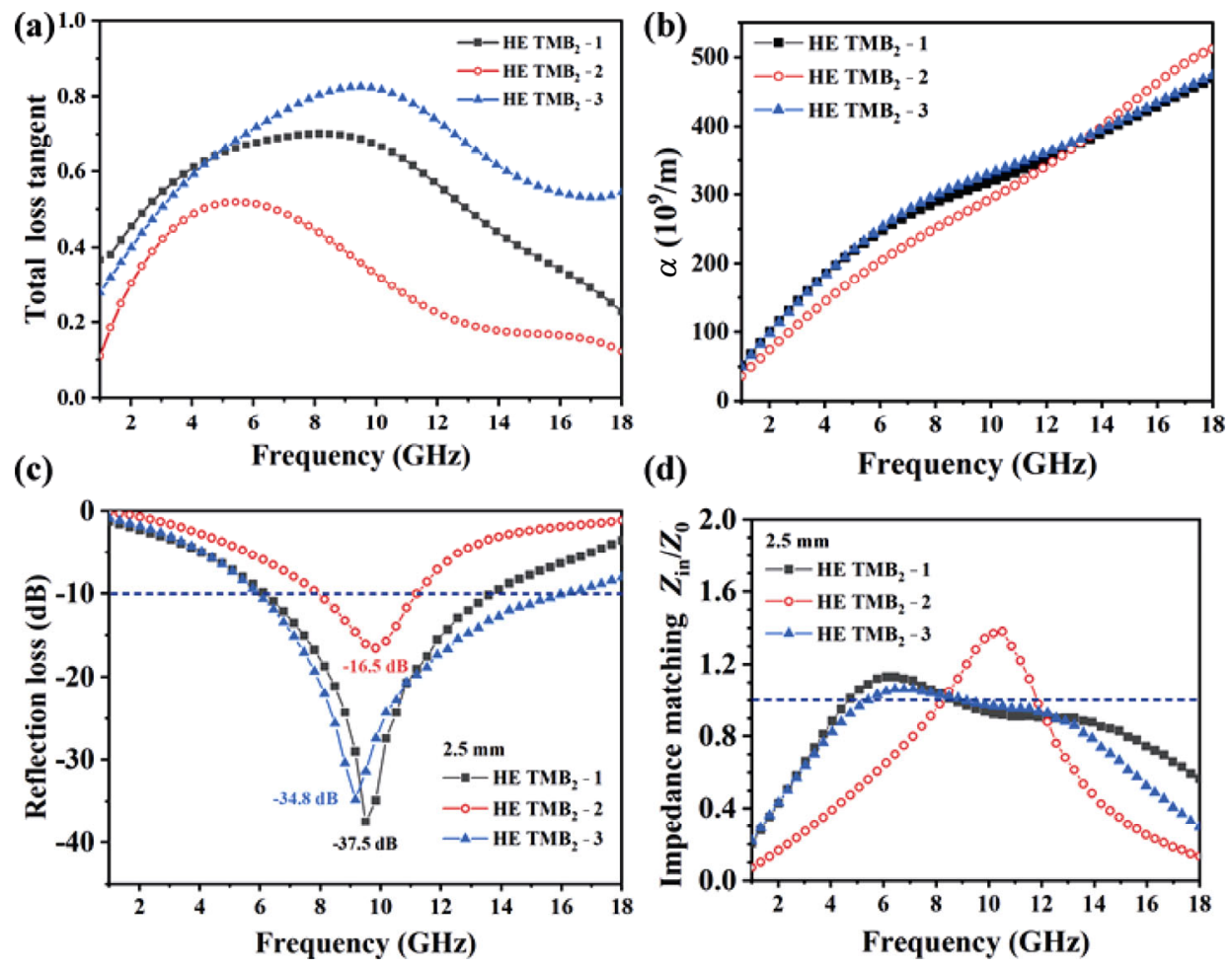

Fig. 11 Frequency dependences of (a) total loss tangent ( $\tan \delta_{\varepsilon}+\tan \delta_{\mu}$ ) and (b) attenuation constant $(\alpha)$; comparison of (c) RL values and (d) impedance match $\left(Z_{\text {in }} / Z_{0}\right)$ of $\mathrm{HE} \mathrm{TMB}_{2} \mathrm{~s}$.

effects of dual losses into account, the attenuation constant $(\alpha)$ is used for a comprehensive comparison of the dissipation capability of $\mathrm{HE} \mathrm{TMB}_{2} \mathrm{~S}$ according to Eq. (8) [7]:

$$
\begin{aligned}
& \alpha=\frac{\sqrt{2} \pi f}{c} \\
& \times \sqrt{\left(\mu^{\prime \prime} \varepsilon^{\prime \prime}-\mu^{\prime} \varepsilon^{\prime}\right)+\sqrt{\left(\mu^{\prime \prime} \varepsilon^{\prime \prime}-\mu^{\prime} \varepsilon^{\prime}\right)^{2}+\left(\mu^{\prime} \varepsilon^{\prime \prime}+\mu^{\prime \prime} \varepsilon^{\prime}\right)^{2}}}
\end{aligned}
$$

As shown in Fig. 11(b), the $\alpha$ values of $\mathrm{HE} \mathrm{TMB}_{2}-1$ and $\mathrm{HE} \mathrm{TMB}_{2}-3$ are comparable, and both are larger than those of $\mathrm{HE} \mathrm{TMB}_{2}-2$ below $14 \mathrm{GHz}$ but are exceeded by $\mathrm{HE} \mathrm{TMB}_{2}-2$ above $14 \mathrm{GHz}$, indicating that three $\mathrm{HE} \mathrm{TMB}_{2} \mathrm{~S}$ exhibit frequency dependent dissipation capability. To assess the EM wave absorption performance, RL as a critical criterion is simulated by Eqs. (4) and (5). As depicted in Fig. 11(c), at the same thickness of $2.5 \mathrm{~mm}, \mathrm{HE} \mathrm{TMB}_{2}-1$ and $\mathrm{HE} \mathrm{TMB}_{2}-3$ exhibit good EM wave absorption capacity at $\mathrm{X}$ band (8-12 GHz), while the $\mathrm{RL}_{\text {min }}$ value of $\mathrm{HE} \mathrm{TMB}_{2}-2$ is considerably smaller, which is ascribed to two main factors, namely, the weaker coupling losses and the poorer impedance match. The impedance match is determined by $Z\left(Z_{\text {in }} / Z_{0}\right)$ values. When the $Z$ value is close to 1 , it implies better impedance match, otherwise the EM wave tends to be reflected on the surface of microwave absorbers. As displayed in Fig. 11(d), at the same thickness of $2.5 \mathrm{~mm}$, the $Z$ values of $\mathrm{HE} \mathrm{TMB}_{2}-1$ and $\mathrm{HE} \mathrm{TMB}_{2}-3$ are equal to 1 across a wide frequency range, indicating their ideal impedance matching, while those of $\mathrm{HE} \mathrm{TMB}_{2}-2$ are relatively distant from 1. Notably, as a result of strong dissipation capability and ideal impedance matching, with the thickness of $2.5 \mathrm{~mm}$, the minimum reflection loss $\left(\mathrm{RL}_{\text {min }}\right)$ and $\mathrm{EAB}$ of $\mathrm{HE} \mathrm{TMB}_{2}-1$ and $\mathrm{HE} \mathrm{TMB}_{2}-3$ are $-37.5 \mathrm{~dB}, 7.1 \mathrm{GHz}$ and $-34.8 \mathrm{~dB}$, and $10.0 \mathrm{GHz}$, respectively. It is worth noting that $\mathrm{HE} \mathrm{TMB}_{2}-1$ and $\mathrm{HE} \mathrm{TMB} 2-3$ exhibit wide effective absorption bandwidth, which is ascribed to ideal impedance match over a wide frequency range.

According to Eqs. (4) and (5), the thickness of microwave absorbers $(d)$ also has impacts on the RL and $Z$ values. Thus, Fig. 12 plots the $Z$ and RL contour maps of $\mathrm{HE} \mathrm{TMB}_{2} \mathrm{~S}$ related to the thickness $(d)$ and frequency $(f)$. It is found that strong absorption capacities are realized in $\mathrm{HE} \mathrm{TMB}_{2} \mathrm{~s}$, and the optimal $\mathrm{RL}_{\text {min }}$ values at matching frequency and thickness of $\mathrm{HE} \mathrm{TMB}_{2}-1, \mathrm{HE} \mathrm{TMB}_{2}-2$, and $\mathrm{HE} \mathrm{TMB}_{2}-3$ are $-59.6 \mathrm{~dB}(8.48 \mathrm{GHz}, 2.68 \mathrm{~mm}),-47.2 \mathrm{~dB}(16.9 \mathrm{GHz}$, $4.40 \mathrm{~mm})$, and $-56.2 \mathrm{~dB}(8.48 \mathrm{GHz}, 2.63 \mathrm{~mm})$, 

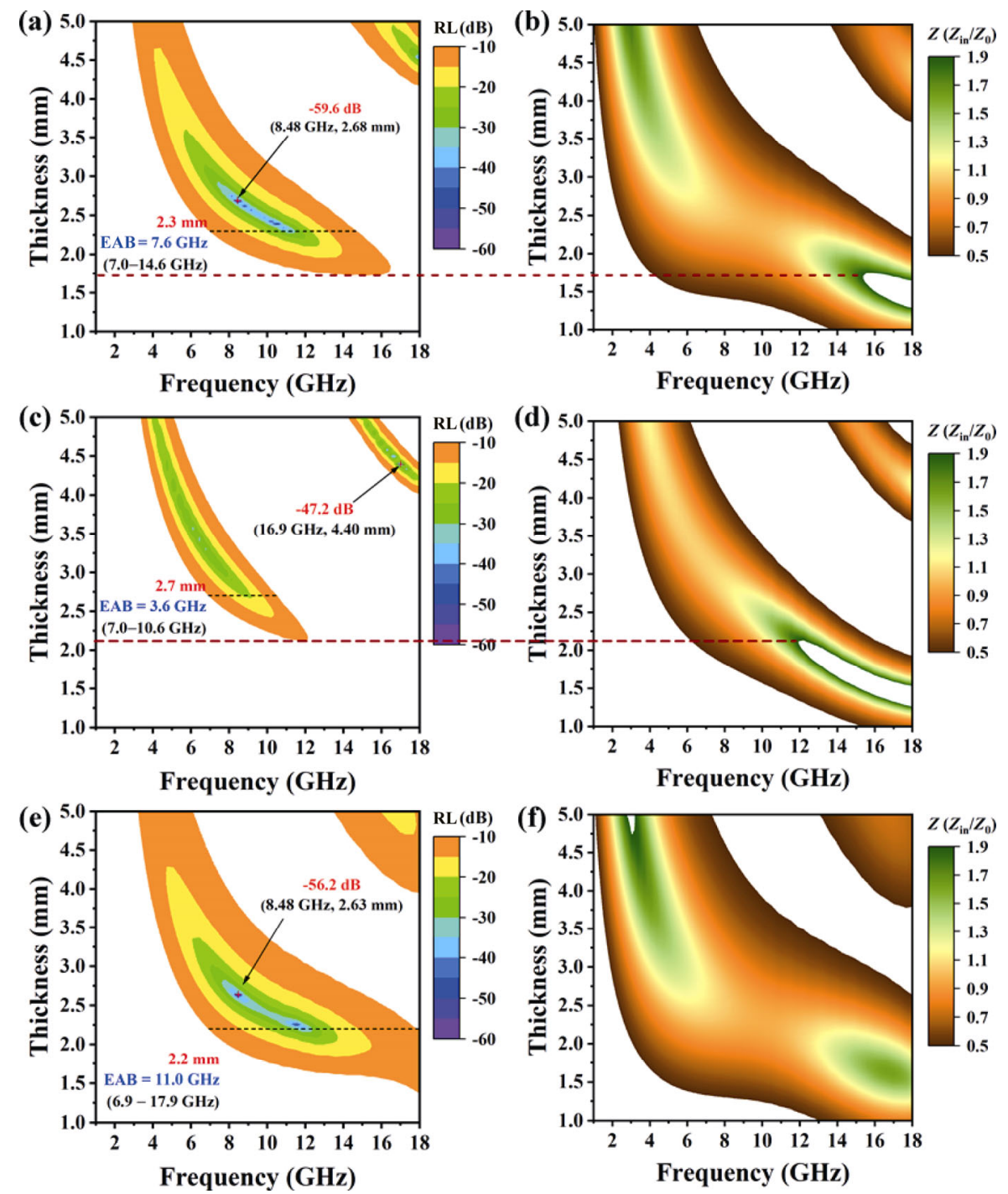

Fig. 12 Contour maps of RL and impedance match $(Z)$ values of (a, b) HE TMB $2-1$, (c, d) $\mathrm{HE} \mathrm{TMB}_{2}-2$, and (e, f) $\mathrm{HE} \mathrm{TMB}_{2}-3$.

respectively, when $Z$ values are close to 1 . Moreover, it can be concluded that the impedance matching can be tailored by compositional design, as a direct result of adjustable electromagnetic parameters in Fig. 9. In specific, compared with $\mathrm{HE} \mathrm{TMB}_{2}-1$, the incorporation of $\mathrm{CrB}_{2}$ into $\mathrm{HE} \mathrm{TMB}_{2}-3$ greatly improves the impedance match over the testing frequency span, which is helpful to obtain strong and broadband absorbing capability, while the introduction of $\mathrm{TiB}_{2}$ in $\mathrm{HE}_{\mathrm{TMB}}-2$ results in the opposite effects. To elaborate the effects of impedance matching on the effective absorption bandwidth, based on the definition of effective bandwidth, we can conclude that the effective absorption occurs when $0.52 \leqslant Z \leqslant 1.93$ by solving Eq. (9) [6]:

$$
\mathrm{RL}=20 \log \left|\left(Z_{\text {in }}-Z_{0}\right) /\left(Z_{\text {in }}+Z_{0}\right)\right| \leqslant-10 \mathrm{~dB}
$$

Drawn from the comparison of $Z$ and $R L$ contour maps in Fig. 12, it is found that the effective absorption areas of $\mathrm{HE} \mathrm{TMB}_{2} \mathrm{~s}$ locate within the regions where $0.52 \leqslant Z \leqslant$ 1.93. According to the quarterwavelength model [47]:

$$
d_{\mathrm{m}}=\frac{n c}{4 f_{\mathrm{m}} \sqrt{\left|\varepsilon_{\mathrm{r}}\right|\left|\mu_{\mathrm{r}}\right|}}
$$

where $d_{\mathrm{m}}$ is the matching thickness, $n=1,3,5, \ldots$, and $f_{\mathrm{m}}$ is the matching frequency. Obviously, the matching thickness of microwave absorbers tends to decrease when the $f_{\mathrm{m}}$ elevates. Notably, the boosting magnetic loss capability in $\mathrm{HE} \mathrm{TMB}_{2}-3$ especially in the high frequency range as shown in Fig. 10(b) leads to better impedance matching, which is of great significance because the matching thickness can be effectively reduced at high frequencies. As proven in Figs. 12(a)-12(d), the absences of effective absorption with 
thin thickness in $\mathrm{HE} \mathrm{TMB}_{2}-1$ and $\mathrm{HE} \mathrm{TMB}_{2}-2$ are ascribed to impedance mismatch at high frequency ranges, while wide effective absorption is achieved in $\mathrm{HE} \mathrm{TMB}_{2}-3$ due to the improved impedance matching in Figs. 12(e) and 12(f). Besides, the effective absorptions at high frequency (14-18 GHz) with thickness above 4 $\mathrm{mm}$ in $\mathrm{HE} \mathrm{TMB}_{2} \mathrm{~S}$ are identified, which occur when good impedance match is realized with cancellation series $n$ equal to 3 . Moreover, the strong absorption $(\mathrm{RL}=-47.2 \mathrm{~dB})$ in $\mathrm{HE} \mathrm{TMB}_{2}-2$ at $16.9 \mathrm{GHz}$ with a thickness of $4.48 \mathrm{~mm}$ is resulted from synergistic effects of strong attenuation capability $(\alpha)$ and good impedance matching $(Z)$ as shown in Figs. 11(b) and 12(d). From Figs. 12(a), 12(c), and 12(e), the optimal effective absorption bandwidth and the corresponding matching thickness of $\mathrm{HE} \mathrm{TMB}_{2}-1$, $\mathrm{HE} \mathrm{TMB}_{2}-2$, and $\mathrm{HE} \mathrm{TMB}_{2}-3$ are $7.6 \mathrm{GHz}$ (at $2.3 \mathrm{~mm}$ ), $3.6 \mathrm{GHz}$ (at $2.7 \mathrm{~mm}$ ), and $11.0 \mathrm{GHz}$ (at $2.2 \mathrm{~mm}$ ), respectively. In detail, effective absorption (RL $<-10 \mathrm{~dB}$ ) can be realized in $\mathrm{HE} \mathrm{TMB}_{2}-3$ at frequency range of 4-18 $\mathrm{GHz}$ by tuning the thickness within $1.5-5 \mathrm{~mm}$, which covers the total $\mathrm{C}$ band $(4-8 \mathrm{GHz}), \mathrm{X}$ band $(8-12$ $\mathrm{GHz})$, and $\mathrm{Ku}$ band $(12-18 \mathrm{GHz})$. To illustrate the superior EM wave absorption performance of $\mathrm{HE}$ $\mathrm{TMB}_{2}$ s, Fig. 13 summarizes the optimized EAB and $\mathrm{RL}$ values of three $\mathrm{HE} \mathrm{TMB}_{2} \mathrm{~S}$ and some currently reported EM wave absorbers of sulfides based (CF@MoS 2 [6], MoS [12]), MXenes ( $\mathrm{Ti}_{3} \mathrm{C}_{2}$ [14]), ferrites $\left(\mathrm{Fe}_{3} \mathrm{O}_{4}\right.$ [15], $\mathrm{C} @ \mathrm{BaMg}_{0.2} \mathrm{Co}_{0.8} \mathrm{TiFe}_{10} \mathrm{O}_{19}$ [16], $\left.\mathrm{Ba}_{0.8} \mathrm{La}_{0.2} \mathrm{Co}_{0.9} \mathrm{Zn}_{1.1} \mathrm{Fe}_{16} \mathrm{O}_{27}[17]\right)$, metal and alloys (Fe [18], FeCo [19], CoNi [20]), carbides ( $\mathrm{HfC} / \mathrm{SiC}$ [25],

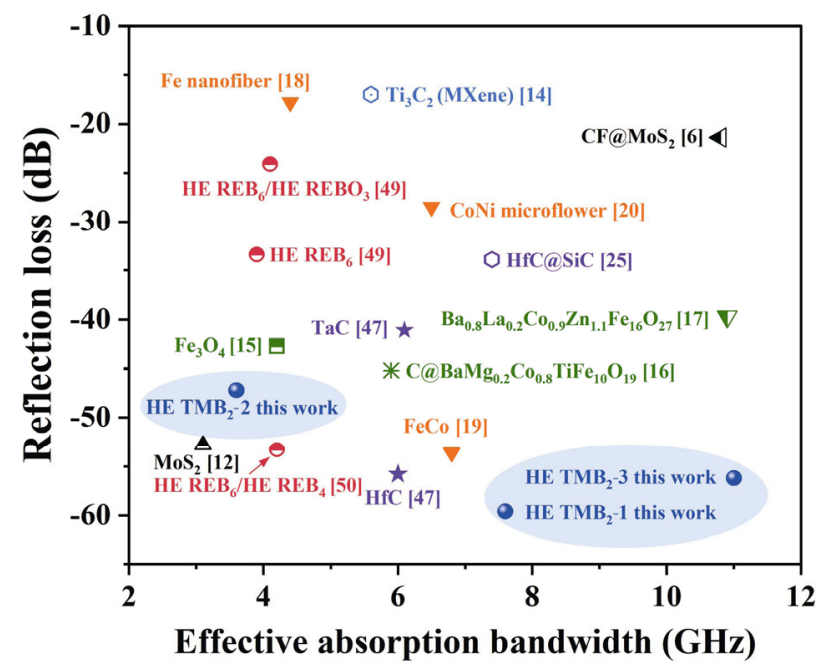

Fig. 13 Comparison of optimal optimized EAB and RL values of $\mathrm{HE} \mathrm{TMB}_{2} \mathrm{~s}$ and those of current EW wave absorbers.
HfC [47], TaC [47]), and high-entropy borides (HE $\mathrm{REB}_{6}$ [49], HE REB 6 /HE REBO 3 [49], HE REB 6 /HE $\mathrm{REB}_{4}$ [50]). It is worth mentioning that the EM wave absorbers locating in lower-right corner in Fig. 13 are the target of many investigations, where stands $\mathrm{HE}$ $\mathrm{TMB}_{2}-1$ and $\mathrm{HE} \mathrm{TMB}_{2}-3$. It can be seen that $\mathrm{HE}$ $\mathrm{TMB}_{2}-1$ and $\mathrm{HE} \mathrm{TMB}_{2}-3$ possess the widest $\mathrm{EAB}$ and smallest RL values among these EM wave absorbers, demonstrating superior EM wave absorption performance.

Drawn from the above analyses, strong and broadband absorption capability can be achieved by tailoring the impedance matching through designing $\mathrm{HE} \mathrm{TMB}_{2} \mathrm{~S}$, i.e., the dielectric loss can be adjusted by reducing the electrical conductivity and the magnetic loss can be enhanced by incorporating components with more dissipation pathways of magnetic field energy.

\section{Conclusions}

In summary, three $\mathrm{HE} \mathrm{TMB}_{2}$ powders with nominal equimolar ratio including $\mathrm{HE} \mathrm{TMB}_{2}-1(\mathrm{TM}=\mathrm{Zr}$, Hf, $\mathrm{Nb}, \mathrm{Ta}), \mathrm{HE} \mathrm{TMB}_{2}-2(\mathrm{TM}=\mathrm{Ti}, \mathrm{Zr}, \mathrm{Hf}, \mathrm{Nb}, \mathrm{Ta})$, and $\mathrm{HE} \mathrm{TMB}_{2}-3(\mathrm{TM}=\mathrm{Cr}, \mathrm{Zr}, \mathrm{Hf}, \mathrm{Nb}, \mathrm{Ta})$ were designed and successfully synthesized, which demonstrate promising EM wave absorption performance.

Theoretical calculations based on DFT reveal that $\mathrm{TiB}_{2}$ possesses the highest degree of ionicity, and $\mathrm{CrB}_{2}$ exhibits partially polarized spin, while $d$-orbital splitting effects are commonly observed among $\mathrm{TMB}_{2} \mathrm{~s}$. Besides, the introduction of $\mathrm{CrB}_{2}$ into $\mathrm{TiB}_{2}$ is helpful to boost the partial spin polarization and the permeability. These features are closely related to the electromagnetic parameters of the as-synthesized $\mathrm{HE} \mathrm{TMB}_{2} \mathrm{~S}$. XRD analyses indicate that the main phases of $\mathrm{AlB}_{2}$-type $\mathrm{HE}$ $\mathrm{TMB}_{2}$ with multi-principle TM elements are formed with minor impurities. The final cation composition of $\mathrm{HE} \mathrm{TMB}_{2}-3$ is found distant from the nominal one, which is determined as $\left(\mathrm{Cr}_{0.139} \mathrm{Zr}_{0.210} \mathrm{Hf}_{0.219} \mathrm{Nb}_{0.216} \mathrm{Ta}_{0.216}\right) \mathrm{B}_{2}$ by ICP-OES. Through SEM analysis, plate-like and column-like particles are commonly observed, and the average particle size of $\mathrm{HE} \mathrm{TMB}_{2}-3$ is $2.22 \mu \mathrm{m}$, nearly tripling those of $\mathrm{HE} \mathrm{TMB}_{2}-1 \quad(0.83 \mu \mathrm{m})$ and $\mathrm{HE}$ $\mathrm{TMB}_{2}-2(0.78 \mu \mathrm{m})$. STEM-EDS analysis reveals that the distribution of multiple $\mathrm{TM}$ elements in $\mathrm{HE}$ $\mathrm{TMB}_{2}-3$ is homogenous.

As the synergistic effects of the reduced electrical conductivity and the boosted magnetic losses, the target of tuning the balance between dielectric loss and 
magnetic loss in single phase $\mathrm{HE} \mathrm{TMB}_{2}$ is achieved, leading to good EM wave absorption performance. The optimal $\mathrm{RL}_{\min }$ values at matching frequency and thickness of $\mathrm{HE} \mathrm{TMB}_{2}-1, \mathrm{HE} \mathrm{TMB}_{2}-2$, and $\mathrm{HE} \mathrm{TMB}_{2}-3$ are $-59.6 \mathrm{~dB}(8.48 \mathrm{GHz}, 2.68 \mathrm{~mm}),-47.2 \mathrm{~dB}(16.9$ $\mathrm{GHz}, 4.40 \mathrm{~mm})$, and $-56.2 \mathrm{~dB}(8.48 \mathrm{GHz}, 2.63 \mathrm{~mm})$, respectively. In addition to strong attenuation capability, broadband absorption capabilities are also demonstrated. The optimal effective absorption bandwidth and the corresponding matching thickness of $\mathrm{HE} \mathrm{TMB}_{2}-1, \mathrm{HE}$ $\mathrm{TMB}_{2}-2$, and $\mathrm{HE} \mathrm{TMB}_{2}-3$ are $7.6 \mathrm{GHz}$ (at $2.3 \mathrm{~mm}$ ), $3.6 \mathrm{GHz}$ (at $2.7 \mathrm{~mm}$ ), and $11.0 \mathrm{GHz}$ (at $2.2 \mathrm{~mm}$ ), respectively. The introduction of $\mathrm{CrB}_{2}$ in $\mathrm{HE} \mathrm{TMB}_{2}-3$ greatly improves the impedance match, thus leading to high efficiency and broadband absorption performance. Considering good thermal stability, oxidation and corrosion resistance, $\mathrm{HE} \mathrm{TMB}_{2}$ ceramics are promising as a new type of EM wave absorbing materials that cater the needs for applications in harsh serving environments.

\section{Acknowledgements}

We gratefully acknowledge financial supports from the National Natural Science Foundation of China (Grant Nos. 51972089, 51672064, and U1435206).

\section{References}

[1] Erogul O, Oztas E, Yildirim I, et al. Effects of electromagnetic radiation from a cellular phone on human sperm motility: An in vitro study. Arch Med Res 2006, 37: 840-843.

[2] Jamshed MA, Héliot F, Brown TWC. A survey on electromagnetic risk assessment and evaluation mechanism for future wireless communication systems. IEEE $J$ Electromagn RF Microwaves Med Biology 2020, 4: 24-36.

[3] Raghvendra M, Aastha D, Priyanka M, et al. Recent progress in electromagnetic absorbing materials. In Advanced Materials for Electromagnetic Shielding: Fundamentals, Properties, and Applications. Jaroszewski M, Tomas S, Rane AV, Eds. New Jersey: John Wiley \& Sons, 2018.

[4] Green M, Chen XB. Recent progress of nanomaterials for microwave absorption. J Materiomics 2019, 5: 503-541.

[5] Wang C, Murugadoss V, Kong J, et al. Overview of carbon nanostructures and nanocomposites for electromagnetic wave shielding. Carbon 2018, 140: 696-733.

[6] Zhang WD, Zhang X, Zhu Q, et al. High-efficiency and wide-bandwidth microwave absorbers based on $\mathrm{MoS}_{2}$-coated carbon fiber. J Colloid Interface Sci 2021,
586: $457-468$.

[7] Qi XS, Xu JL, Hu Q, et al. Metal-free carbon nanotubes: synthesis, and enhanced intrinsic microwave absorption properties. Sci Rep 2016, 6: 28310.

[8] Wang C, Han XJ, Xu P, et al. The electromagnetic property of chemically reduced graphene oxide and its application as microwave absorbing material. Appl Phys Lett 2011, 98: 072906.

[9] Zhang P, Han XJ, Kang LL, et al. Synthesis and characterization of polyaniline nanoparticles with enhanced microwave absorption. RSC Adv 2013, 3: 12694.

[10] Green M, Liu Z, Xiang P, et al. Doped, conductive $\mathrm{SiO}_{2}$ nanoparticles for large microwave absorption. Light Sci Appl 2018, 7: 87.

[11] Chen YJ, Cao MS, Wang TH, et al. Microwave absorption properties of the $\mathrm{ZnO}$ nanowire-polyester composites. Appl Phys Lett 2004, 84: 3367-3369.

[12] Su XL, Ning J, Jia Y, et al. Flower-like $\mathrm{MoS}_{2}$ nanospheres: a promising material with good microwave absorption property in the frequency range of $8.2-12.4 \mathrm{GHz}$. Nano 2018, 13: 1850084.

[13] Yang HJ, Cao WQ, Zhang DQ, et al. NiO hierarchical nanorings on SiC: Enhancing relaxation to tune microwave absorption at elevated temperature. ACS Appl Mater Interfaces 2015, 7: 7073-7077.

[14] Qing YC, Zhou WC, Luo F, et al. Titanium carbide (MXene) nanosheets as promising microwave absorbers. Ceram Int 2016, 42: 16412-16416.

[15] Zou Z, Xuan AG, Yan ZG, et al. Preparation of $\mathrm{Fe}_{3} \mathrm{O}_{4}$ particles from copper/iron ore cinder and their microwave absorption properties. Chem Eng Sci 2010, 65: 160-164.

[16] Chen J, Wang ML, Meng PY, et al. Electromagnetic and microwave absorption properties of the core-shell structured $\mathrm{C} @ \mathrm{BaMg}_{0.2} \mathrm{Co}_{0.8} \mathrm{TiFe}_{10} \mathrm{O}_{19}$ nanoparticles. $J$ Mater Sci: Mater Electron 2017, 28: 2100-2106.

[17] Deng LW, Ding L, Zhou KS, et al. Electromagnetic properties and microwave absorption of W-type hexagonal ferrites doped with $\mathrm{La}^{3+}$. J Magn Magn Mater 2011, 323: 1895-1898.

[18] Liu QC, Zi ZF, Wu DJ, et al. Controllable synthesis and morphology-dependent microwave absorption properties of iron nanocrystals. J Mater Sci 2012, 47: 1033-1037.

[19] Yang Y, Xu CL, Xia YX, et al. Synthesis and microwave absorption properties of FeCo nanoplates. J Alloys Compd 2010, 493: 549-552.

[20] Liu QH, Cao Q, Zhao XB, et al. Insights into size-dominant magnetic microwave absorption properties of $\mathrm{CoNi}$ microflowers via off-axis electron holography. ACS Appl Mater Interfaces 2015, 7: 4233-4240.

[21] Wallace J. Broadband magnetic microwave absorbers: fundamental limitations. Trans Magn 1993, 29: 42094214.

[22] Wu NN, Liu C, Xu DM, et al. Enhanced electromagnetic wave absorption of three-dimensional porous $\mathrm{Fe}_{3} \mathrm{O}_{4} / \mathrm{C}$ composite flowers. ACS Sustainable Chem Eng 2018, 6: 


\section{1-12480.}

[23] He J, Liu S, Deng LW, et al. Tunable electromagnetic and enhanced microwave absorption properties in $\mathrm{CoFe}_{2} \mathrm{O}_{4}$ decorated $\mathrm{Ti}_{3} \mathrm{C}_{2}$ MXene composites. Appl Surf Sci 2020, 504: 144210.

[24] Liu JL, Liang $\mathrm{HS}$, Wu HJ. Hierarchical flower-like $\mathrm{Fe}_{3} \mathrm{O}_{4} / \mathrm{MoS}_{2}$ composites for selective broadband electromagnetic wave absorption performance. Compos $A$ : Appl Sci Manuf 2020, 130: 105760.

[25] Hou Y, Cheng LF, Zhang YN, et al. Enhanced flexibility and microwave absorption properties of $\mathrm{HfC} / \mathrm{SiC}$ nanofiber mats. ACS Appl Mater Interfaces 2018, 10: 29876-29883.

[26] Zhao B, Li Y, Zeng Q, et al. Galvanic replacement reaction involving core-shell magnetic chains and orientationtunable microwave absorption properties. Small 2020, 16: 2003502.

[27] Liu Y, Cui TT, Wu T, et al. Excellent microwave-absorbing properties of elliptical $\mathrm{Fe}_{3} \mathrm{O}_{4}$ nanorings made by a rapid microwave-assisted hydrothermal approach. Nanotechnology 2016, 27: 165707.

[28] Fahrenholtz W, Hilmas G, Talmy I, et al. Refractory diborides of zirconium and hafnium. J Am Ceram Soc 2007, 90: $1347-1364$.

[29] Zhang GJ, Ni DW, Zou J, et al. Inherent anisotropy in transition metal diborides and microstructure/property tailoring in ultra-high temperature ceramics-A review. $J$ Eur Ceram Soc 2018, 38: 371-389.

[30] Vajeeston P, Ravindran P, Ravi C, et al. Electronic structure, bonding, and ground-state properties of $\mathrm{AlB}_{2}$-type transition-metal diborides. Phys Rev B 2001, 63: 045115.

[31] Zhou YC, Xiang HM, Feng ZH, et al. General trends in electronic structure, stability, chemical bonding and mechanical properties of ultrahigh temperature ceramics $\mathrm{TMB}_{2}(\mathrm{TM}=$ transition metal). J Mater Sci Technol 2015, 31: $285-294$.

[32] Juretschke H, Steinitz R. Hall effect and electrical conductivity of transition-metal diborides. J Phys Chem Solids 1958, 4: 118-127.

[33] Neelakanta P. Handbook of Electromagnetic Materials: Monolithic and Composite Versions and Their Applications. Boca Raton (USA): CRC Press, 1995.

[34] Jian X, Tian W, Li JY, et al. High-temperature oxidation-resistant $\mathrm{ZrN}_{0.4} \mathrm{~B}_{0.6} / \mathrm{SiC}$ nanohybrid for enhanced microwave absorption. ACS Appl Mater Interfaces 2019, 11: $15869-15880$.

[35] Walter H. Electronic Structure and the Properties of Solids: The Physics of the Chemical Bond. New York (USA): Dover Publications, 2012.

[36] Anderson P. Absence of diffusion in certain random lattices. Phys Rev 1958, 109: 1492-1505.

[37] Manijeh R. Fundamentals of Solid State Engineering. New York (USA): Springer, 2006.

[38] Xiang HM, Xing Y, Dai FZ, et al. High-entropy ceramics: Present status, challenges, and a look forward. J Adv Ceram 2021, 10: 385-441.
[39] Rost C, Sachet E, Borman T, et al. Entropy-stabilized oxides. Nat Commun 2015, 6: 8485.

[40] Kao YF, Chen SK, Chen TJ, et al. Electrical, magnetic, and Hall properties of $\mathrm{Al}_{x} \mathrm{CoCrFeNi}$ high-entropy alloys. $J$ Alloys Compd 2011, 509: 1607-1614.

[41] Castaing J, Costa P. Properties and Uses of Diborides. In Boron and Refractory Borides. Matkovich VI, Ed. Berlin: Springer, 2012: 390-412.

[42] Grechnev G, Fedorchenko A, Logosha A, et al. Electronic structure and magnetic properties of transition metal diborides. J Alloys Compd 2009, 481: 75-80.

[43] Barnes R, Creel R. Chromium-like antiferromagnetic behavior of $\mathrm{CrB}_{2}$. Phys Lett A 1969, 29: 203-204.

[44] Funahashi S, Hamaguchi Y, Tanaka T, et al. Helical magnetic structure in $\mathrm{CrB}_{2}$. Solid State Commun 1977, 23 : 859-862.

[45] Mabbs FE, Collison D. Electron Paramagnetic Resonance of $d$ Transition Metal Compounds. Amsterdam (the Netherlands): Elsevier, 1992.

[46] Kolodiazhnyi T, Petric A. Analysis of point defects in polycrystalline $\mathrm{BaTiO}_{3}$ by electron paramagnetic resonance. J Phys Chem Solids 2003, 64: 953-960.

[47] Zhou YC, Zhao B, Chen H, et al. Electromagnetic wave absorbing properties of TMCs (TM=Ti, Zr, Hf, Nb and Ta) and high entropy $\left(\mathrm{Ti}_{0.2} \mathrm{Zr}_{0.2} \mathrm{Hf}_{0.2} \mathrm{Nb}_{0.2} \mathrm{Ta}_{0.2}\right)$ C. J Mater Sci Technol 2021, 74: 105-118.

[48] Chen H, Zhao B, Zhao ZF, et al. Achieving strong microwave absorption capability and wide absorption bandwidth through a combination of high entropy rare earth silicide carbides/rare earth oxides. J Mater Sci Technol 2020, 47: 216-222.

[49] Zhang WM, Zhao B, Xiang HM, et al. One-step synthesis and electromagnetic absorption properties of high entropy rare earth hexaborides $\left(\mathrm{HE} \mathrm{REB}_{6}\right)$ and high entropy rare earth hexaborides/borates $\left(\mathrm{HE} \mathrm{REB}_{6} / \mathrm{HE} \mathrm{REBO}_{3}\right)$ composite powders. $J$ Adv Ceram 2021, 10: 62-77.

[50] Zhang WM, Zhao B, Ni N, et al. High entropy rare earth hexaborides/tetraborides (HE REB6/HE REB4) composite powders with enhanced electromagnetic wave absorption performance. J Mater Sci Technol 2021, 87: 155-166.

[51] Zhao ZF, Xiang HM, Dai FZ, et al. (TiZrHf) $\mathrm{P}_{2} \mathrm{O}_{7}$ : An equimolar multicomponent or high entropy ceramic with good thermal stability and low thermal conductivity. $J$ Mater Sci Technol 2019, 35: 2227-2231.

[52] Zhao ZF, Chen H, Xiang HM, et al. High entropy defective fluorite structured rare-earth niobates and tantalates for thermal barrier applications. $J$ Adv Ceram 2020, 9: 303-311.

[53] Sun YN, Xiang HM, Dai FZ, et al. Preparation and properties of CMAS resistant bixbyite structured high-entropy oxides $\mathrm{RE}_{2} \mathrm{O}_{3}(\mathrm{RE}=\mathrm{Sm}, \mathrm{Eu}, \mathrm{Er}, \mathrm{Lu}, \mathrm{Y}$, and $\mathrm{Yb}$ ): Promising environmental barrier coating materials for $\mathrm{Al}_{2} \mathrm{O}_{3 \mathrm{f}} / \mathrm{Al}_{2} \mathrm{O}_{3}$ composites. $J$ Adv Ceram 2021, 10: 596-613.

[54] Zhou JY, Zhang JY, Zhang F, et al. High-entropy carbide: A novel class of multicomponent ceramics. Ceram Int 2018, 


\section{4: 22014-22018.}

[55] Dong Y, Ren K, Lu YH, et al. High-entropy environmental barrier coating for the ceramic matrix composites. $J$ Eur Ceram Soc 2019, 39: 2574-2579.

[56] Clark SJ, Segall MD, Pickard CJ, et al. First principles methods using CASTEP. Z Krist Cryst Mater 2005, 220: 567-570.

[57] Vanderbilt D. Soft self-consistent pseudopotentials in a generalized eigenvalue formalism. Phys Rev B Condens Matter 1990, 41: 7892-7895.

[58] Perdew J, Burke K, Ernzerhof M. Generalized gradient approximation made simple. Phys Rev Lett 1996, 77: 3865-3868.

[59] Monkhorst HJ, Pack JD. Special points for brillouin-zone integrations. Phys Rev B 1976, 13: 5188-5192.

[60] Pfrommer BG, Côté M, Louie SG, et al. Relaxation of crystals with the quasi-newton method. J Comput Phys 1997, 131: 233-240.

[61] Segall M, Pickard C, Shah R, et al. Population analysis in plane wave electronic structure calculations. Mol Phys 1996, 89: 571-577.

[62] Segall M, Shah R, Pickard C, et al. Population analysis of plane-wave electronic structure calculations of bulk materials. Phys Rev B Condens Matter 1996, 54: 1631716320.

[63] Joachim K. Polarized Electrons. Berlin (Germany): Springer, 1976.

[64] Gu JF, Zou J, Sun SK, et al. Dense and pure high-entropy metal diboride ceramics sintered from self-synthesized powders via boro/carbothermal reduction approach. Sci China Mater 2019, 62: 1898-1909.

[65] Walton W. Feret's statistical diameter as a measure of particle size. Nature 1948, 162: 329-330.

[66] Kumar R, Mishra M, Sharma B, et al. Electronic structure and elastic properties of $\mathrm{TiB}_{2}$ and $\mathrm{ZrB}_{2}$. Comput Mater Sci 2012, 61: 150-157.
[67] Charles K. Introduction to Solid State Physics. New York (USA): Wiley, 1996.

[68] Yao TK, Wang YC, Li H, et al. A universal trend of structural, mechanical and electronic properties in transition metal $(\mathrm{M}=\mathrm{V}, \mathrm{Nb}$, and $\mathrm{Ta})$ borides: Firstprinciple calculations. Comput Mater Sci 2012, 65: 302308.

[69] Beruto D, Barco L, Belleri G. On the stability of refractory materials under industrial vacuum conditions: $\mathrm{Al}_{2} \mathrm{O}_{3}, \mathrm{BeO}$, $\mathrm{CaO}, \mathrm{Cr}_{2} \mathrm{O}_{3}, \mathrm{MgO}, \mathrm{SiO}_{2}, \mathrm{TiO}_{2}$ systems. Ceramurgia Int 1975, 1: 87-93.

[70] Abdel-Hamid AA, Hamar-Thibault S, Hamar R. Crystal morphology of the compound $\mathrm{TiB}_{2}$. J Cryst Growth 1985 , 71: 744-750.

[71] Tilley R. Understanding Solids: The Science of Materials. Chichester (UK): Wiley, 2013.

[72] Van Beek LKH. The Maxwell-Wagner-Sillars effect, describing apparent dielectric loss in inhomogeneous media. Physica 1960, 26: 66-68.

[73] Pople JA. Molecular-orbital theory of diamagnetism. I. An approximate LCAO scheme. J Chem Phys 1962, 37: 53-59.

Open Access This article is licensed under a Creative Commons Attribution 4.0 International License, which permits use, sharing, adaptation, distribution and reproduction in any medium or format, as long as you give appropriate credit to the original author(s) and the source, provide a link to the Creative Commons licence, and indicate if changes were made.

The images or other third party material in this article are included in the article's Creative Commons licence, unless indicated otherwise in a credit line to the material. If material is not included in the article's Creative Commons licence and your intended use is not permitted by statutory regulation or exceeds the permitted use, you will need to obtain permission directly from the copyright holder.

To view a copy of this licence, visit http://creativecommons. org/licenses/by/4.0/. 